$1-2-2017$

\title{
Variation in Reproductive Success Across Captive Populations: Methodological Differences, Potential Biases and Opportunities
}

\author{
Simon C. Griffith \\ simon.griffith@mq.edu.au \\ Ondi L. Crino \\ Samuel C. Andrew \\ Fumiaki Y. Nomano \\ Elizabeth Adkins-Regan \\ See next page for additional authors
}

Follow this and additional works at: https://scholarworks.wm.edu/aspubs

\section{Recommended Citation}

Griffith, Simon C.; Crino, Ondi L.; Andrew, Samuel C.; Nomano, Fumiaki Y.; Adkins-Regan, Elizabeth; AlonsoAlvarez, Carlos; Bailey, Ida E.; Bittner, Stephanie S.; Bolton, Peri E.; Boner, Winnie; Boogert, Neeltje; Boucaud, Ingrid C. A.; Briga, Michael; Buchanan, Katherine L.; Caspers, Barbara A.; Cichon, Mariusz; Clayton, David F.; Deregnaucourt, Sebastien; Forstmeier, Wolfgang; Guillette, Lauren M.; Hartley, Ian R.; Healy, Susan D.; Hill, Davina L.; Swaddle, John; and Varian-Ramos, Claire W., Variation in Reproductive Success Across Captive Populations: Methodological Differences, Potential Biases and Opportunities (2017).

10.1111/eth. 12576

This Other is brought to you for free and open access by the Arts and Sciences at W\&M ScholarWorks. It has been accepted for inclusion in Arts \& Sciences Articles by an authorized administrator of W\&M ScholarWorks. For more information, please contact scholarworks@wm.edu. 


\section{Authors}

Simon C. Griffith, Ondi L. Crino, Samuel C. Andrew, Fumiaki Y. Nomano, Elizabeth Adkins-Regan, Carlos Alonso-Alvarez, Ida E. Bailey, Stephanie S. Bittner, Peri E. Bolton, Winnie Boner, Neeltje Boogert, Ingrid C. A. Boucaud, Michael Briga, Katherine L. Buchanan, Barbara A. Caspers, Mariusz Cichon, David F. Clayton, Sebastien Deregnaucourt, Wolfgang Forstmeier, Lauren M. Guillette, Ian R. Hartley, Susan D. Healy, Davina L. Hill, John Swaddle, and Claire W. Varian-Ramos 


\section{Variation in Reproductive Success Across Captive Populations: Methodological Differences, Potential Biases and Opportunities}

Simon C. Griffith ${ }^{1}$, Ondi L. Crino ${ }^{1}$, Samuel C. Andrew ${ }^{1}$, Fumiaki Y. Nomano ${ }^{1}$, Elizabeth Adkins-Regan ${ }^{2}$, Carlos Alonso-Alvarez ${ }^{3,4}$, Ida E. Bailey ${ }^{5}$, Stephanie S. Bittner ${ }^{6}$, Peri E. Bolton ${ }^{1}$, Winnie Boner ${ }^{7}$, Neeltje Boogert $^{8}$, Ingrid C. A. Boucaud ${ }^{9}$, Michael Briga ${ }^{10}$, Katherine L. Buchanan ${ }^{11}$, Barbara A. Caspers ${ }^{12}$, Mariusz Cichon $^{13}$, David F. Clayton ${ }^{14}$, Sebastien Derégnaucourt ${ }^{15}$, Wolfgang Forstmeier ${ }^{16}$, Lauren M. Guillette ${ }^{5}$, Ian R. Hartley ${ }^{17}$, Susan D. Healy ${ }^{5}$, Davina L. Hill ${ }^{7}$, Marie-Jeanne Holveck ${ }^{18,19}$, Laura L. Hurley ${ }^{1}$, Malika Ihle ${ }^{16}$, E. Tobias Krause ${ }^{12,20}$, Mark C. Mainwaring ${ }^{1,17}$, Valeria Marasco ${ }^{7}$, Mylene M. Mariette ${ }^{9,11}$, Meghan S. Martin-Wintle ${ }^{21,22}$, Luke S. C. McCowan ${ }^{1}$, Maeve McMahon ${ }^{14}$, Pat Monaghan ${ }^{7}$, Ruedi G. Nager ${ }^{7}$, Marc Naguib ${ }^{23}$, Andreas Nord ${ }^{24,25}$, Dominique A. Potvin ${ }^{26}$, Nora H. Prior ${ }^{27}$, Katharina Riebel ${ }^{17}$,

Ana A. Romero-Haro ${ }^{3}$, Nick J. Royle ${ }^{28}$, Joanna Rutkowska ${ }^{13}$, Wiebke Schuett ${ }^{29}$, John P. Swaddle ${ }^{30}$, Michael Tobler $^{24}$, Larissa Trompf ${ }^{1}$, Claire W. Varian-Ramos ${ }^{30}$, Clémentine Vignal ${ }^{9}$, Avelyne S. Villain ${ }^{9}$ \& Tony D. Williams ${ }^{31}$

1 Department of Biological Sciences, Macquarie University, Sydney, NSW, Australia

2 Department of Psychology and Department of Neurobiology and Behavior, Cornell University, Ithaca, NY, USA

3 Instituto de Investigación en Recursos Cinegéticos (IREC) - CSIC-UCLM-JCCM, Ciudad Real, Spain

4 Departamento de Ecología Evolutiva, Museo Nacional de Ciencias Naturales - CSIC, Madrid, Spain

5 School of Biology, University of St Andrews, St Andrews, Fife, UK

6 School of Life Sciences, Arizona State University, Tempe, AZ, USA

7 Institute of Biodiversity, Animal Health and Comparative Medicine, College of Medical, Veterinary and Life Sciences, University of Glasgow, Glasgow, UK

8 School of Psychology, University of St Andrews, St Andrews, Fife, UK

9 CNRS UMR 9197 NeuroPSI/ENES, Université de Lyon/Saint-Etienne, Saint-Etienne, France

10 Behavioural Biology, University of Groningen, Groningen, The Netherlands

11 School of Life and Environmental Sciences, Deakin University, Geelong, VIC, Australia

12 Department of Animal Behaviour, Bielefeld University, Bielefeld, Germany

13 Institute of Environmental Sciences, Jagiellonian University, Cracow, Poland

14 Department of Biological and Experimental Psychology, Queen Mary University of London, London, UK

15 Laboratory Ethology Cognition Development, University Paris West, Nanterre, France

16 Department of Behavioural Ecology and Evolutionary Genetics, Max Planck Institute for Ornithology, Seewiesen, Germany

17 Lancaster Environment Centre, Lancaster University, Lancaster, UK

18 Institute of Biology, University of Leiden, Leiden, The Netherlands

19 Biodiversity Research Centre, Earth and Life Institute, Université Catholique de Louvain (UCL), Louvain-la-Neuve, Belgium

20 Institute of Animal Welfare and Animal Husbandry, Friedrich-Loeffler-Institut, Celle, Germany

21 Conservation and Research Department, PDXWildlife, Portland, OR, USA

22 Applied Animal Ecology, Institute for Conservation Research, San Diego Zoo Global, Escondido, CA, USA

23 Behavioural Ecology Group, Department of Animal Sciences, Wageningen, The Netherlands

24 Department of Biology, Lund University, Lund, Sweden

25 Department of Arctic and Marine Biology, University of Tromsø, Tromsø, Norway

26 Advanced Facility for Avian Research, University of Western Ontario, London, ON, Canada

27 Zoology Department, University of British Columbia, Vancouver, BC, Canada

28 Centre for Ecology and Conservation, University of Exeter, Penryn, UK

29 Zoological Institute, University of Hamburg, Hamburg, Germany

30 Biology Department, Institute for Integrative Bird Behaviour Studies, The College of William and Mary, Williamsburg, VA, USA

31 Department of Biological Sciences, Simon Fraser University, Burnaby, BC, Canada

\section{Correspondence}

Simon C. Griffith, Department of Biological Sciences, Macquarie University, Culloden Road, Sydney, NSW 2109, Australia. E-mail: simon.griffith@mq.edu.au

\begin{abstract}
Our understanding of fundamental organismal biology has been disproportionately influenced by studies of a relatively small number of 'model' species extensively studied in captivity. Laboratory populations of model
\end{abstract}


All authors are arranged alphabetically except the first four who made significant contributions to writing and analysis.

Received: September 7, 2016

Initial acceptance: September 28, 2016

Final acceptance: September 28, 2016

R. Bshary

doi: $10.1111 /$ eth. 12576

Keywords: Taeniopygia guttata, zebra finch, reproductive failure, captivity, domestication, husbandry, model species, captive breeding species are commonly subject to a number of forms of past and current selection that may affect experimental outcomes. Here, we examine these processes and their outcomes in one of the most widely used vertebrate species in the laboratory - the zebra finch (Taeniopygia guttata). This important model species is used for research across a broad range of fields, partly due to the ease with which it can be bred in captivity. However despite this perceived amenability, we demonstrate extensive variation in the success with which different laboratories and studies bred their subjects, and overall only $64 \%$ of all females that were given the opportunity, bred successfully in the laboratory. We identify and review several environmental, husbandry, life-history and behavioural factors that potentially contribute to this variation. The variation in reproductive success across individuals could lead to biases in experimental outcomes and drive some of the heterogeneity in research outcomes across studies. The zebra finch remains an excellent captive animal system and our aim is to sharpen the insight that future studies of this species can provide, both to our understanding of this species and also with respect to the reproduction of captive animals more widely. We hope to improve systematic reporting methods and that further investigation of the issues we raise will lead both to advances in our fundamental understanding of avian reproduction as well as to improvements in future welfare and experimental efficiency.

\section{Introduction}

There has been a recent call to improve on the reporting of information supporting empirical work conducted on animals to improve evaluation and interpretation, and facilitate the use of data in further work (Kilkenny et al. 2010). In their paper, Kilkenny et al. (2010) outlined the value of capturing contextual information (e.g. animal backgrounds, housing and husbandry conditions, sample sizes and selection procedures) with a set of guidelines identifying 20 items that should be addressed in each publication. One of the main underlying drivers of this effort was to reduce the amount of clinical research using laboratory animals (through the UK-based National Centre for the Replacement, Refinement and Reduction of Animals in Research). However, in their paper Kilkenny et al. (2010) also highlighted the opportunities that are missed when the context of a particular study is not adequately communicated. While they focused on all animal models, and particularly those used in biomedical research, there were also some clear messages for research in animal behaviour. The issues raised by Kilkenny et al. (2010), and related ones outlined below will result in biases in both experimental selection of subjects and evolutionary selection over both long and short timescales. Here, we outline these issues by focusing solely on the zebra finch (Taeniopygia guttata), although we consider that our central message and recommendations will be more broadly applicable to all species that have already been, or are to be taken, from the wild into the laboratory. Ultimately we hope our work raises an awareness of the effects that the experimental context may have on research outcomes. The issues on which we focus are those that arise from the challenge of trying to breed and maintain animals in a way that captures the extent of natural variation seen in wild populations, but in a controlled environment. Our findings are therefore also relevant to those managing and designing captive breeding programmes for the benefit of animal conservation (Lees \& Wilcken 2009).

In two well-monitored populations of zebra finches in the wild, reproductive attempts typically end in failure. For natural nests that are vulnerable to predation, only $11-35 \%$ of clutches resulted in fledged young (Zann et al. 1995; Griffith et al. 2008). Even when predation was reduced through the provision of nest boxes, only $53 \%$ of clutches resulted in fledged offspring (Griffith et al. 2008). The variation in reproductive success in the wild is an interesting question in evolutionary ecology that must ultimately reflect the individual optimization of many naturally and sexually selected traits. Even in zebra finches that have been brought into captivity, protected from predators, living in standardized environmental conditions and provided with an ad libitum supply of resources, many individuals fail to reproduce. Zebra finches are not the exception to the rule, as individuals in many animals species brought into captive breeding programmes from wild populations fail to 
reproduce to recruitment (Lees \& Wilcken 2009). This failure presumably reflects some of the same selective pressures to those in the wild, as well as additional challenges of living in captivity. Wild animal populations continue to decline at alarming rates (Butchart et al. 2010; Pereira et al. 2010), and captive breeding is becoming an increasingly important tool to guard against extinction in conservation and species management programmes. Thus, careful evaluation of reproductive failure seen in extensive, multi-institutional captive breeding programmes, such as the zebra finch, and other model systems, can provide valuable insight for the planning and design of conservationfocused captive breeding programmes (Slade et al. 2014).

As well as being of interest to evolutionary ecologists, the variation in reproductive success among captive birds is worthy of attention due to the importance of the zebra finch as a model system for captive research across a broad range of areas in evolutionary biology, physiology, animal behaviour, neurobiology and genetics (Zann 1996; Griffith \& Buchanan 2010). It is important to understand how reproductive failure in laboratory populations might affect the ability to replicate studies across laboratories and indeed affect research outcomes themselves. Not all individuals respond similarly when given the opportunity and resources to reproduce: some individuals quickly and repeatedly reproduce regardless of the circumstances, while others fail to reproduce at all over a lifetime in captivity. The variance in reproductive success among individuals within a single population has been the explicit target of some studies (e.g. Alonso-Alvarez et al. 2006; Bolund et al. 2009; McCowan et al. 2014). However, more generally it is ignored in papers, and in practice could lead to the removal of those individuals that do not reproduce well either deliberately or inadvertently from populations and experiments alike. Typically studies focused around reproduction report the sample size of pairs that bred and are included in specific analyses and only rarely is a reference made to additional birds that were given the opportunity but did not lay eggs (e.g. in Gorman et al. 2005, 77\% of females produced a clutch). Even among those individuals that initiate a reproductive attempt, there is variation in their ability to hatch eggs and rear offspring through to independence. Only rarely is this variation specifically the focus of analysis or comment, even in papers that are focused on aspects of reproductive behaviour or physiology. The variation in these aspects of individual reproductive success in domesticated populations will affect the number of offspring that an individual leaves in subsequent generations. As a result, the underlying determinants of this variation are subject to sexual, natural and artificial selection. The variation among individuals in reproductive success in captive populations will include biological traits such as individual behavioural, genetic and physiological differences, and those relating to the physical, nutritional and social environment in which individuals are held. Here, we introduce each key parameter in the context of the zebra finch, before characterizing the variation that exists across laboratory populations in reproductive success.

\section{Part I. Biological Determinants of Variation in Reproductive Success in Captivity}

Genetic background

Zebra finches were first exported to Europe from Australia in the 1870s for the pet trade (Sossinka 1970). Since that time, captive-bred zebra finches have been exported to North America and other parts of the world for breeding (Zann 1996; Forstmeier et al. 2007) where they have subsequently been isolated to an unknown and varying degree at local and national levels. Domesticated zebra finches used in research in Europe and North America are mostly derived from populations maintained by amateur and professional finch breeders who have bred these populations for over a hundred years without an influx of wildcaught birds from Australia (Zann 1996). Typically, captive zebra finches have not been bred with the intention of preserving genetic diversity and natural behaviour, because these are not priorities for the amateur and professional aviculturists who maintain most of the zebra finches in the overall captive population (even though some laboratories may manage their stock to optimize these). Finch breeders are partly driven by the creation of new morphs that are selected by line breeding and backcrossing, to the extent that there are now 30 recognized colour variants, from a single wild-type phenotype (Zann 1996). Even 'wild-type' birds are bred for competitive showing and judged against aesthetics and avicultural standards such as large size. As a result of this history, domestic populations may have diverged genetically from their wild conspecifics, through artificial selection imposed by aviculture, natural selection to captive conditions (Gilligan \& Frankham 2003; Heath et al. 2003), or through genetic drift (Woodworth et al. 2002). Two studies have found morphological differences between wild and domesticated birds, and between different subsets of the domesticated population (Carr \& Zann 1986; Forstmeier et al. 2007). 
Reassuringly, despite this morphological divergence between populations, however, life-history trade-offs between traits appear very similar between wild and domestic birds held in captivity (Tschirren et al. 2009).

To date, just a single study has addressed genetic divergence in the domesticated zebra finch. Forstmeier et al. (2007) used microsatellites to analyse 18 captive research populations and two wild populations. All captive populations had lower allelic diversity than the two wild populations sampled and many populations showed strong differentiation from one another, particularly between the populations from different continents (Forstmeier et al. 2007). While it does support the idea of fragmentation of the domestic population, the limited neutral genetic divergence between populations observed by Forstmeier et al. (2007) does not exclude a higher degree of divergence in functional traits across these domestic populations.

Although many researchers work with 'wild-type' birds, the presence of the colour variants in the background population, or directly in some studies, raises some issues. First, the degree of melanin pigmentation in animals (a likely target of much artificial selection) correlates with various life-history traits (Meunier et al. 2011), through trade-offs associated with the melanocortin system itself (Ducrest et al. 2008), and as a component of behavioural syndromes (McKinnon \& Pierotti 2010; Emaresi et al. 2014). Relatively few studies have specifically examined the effects of colour variants on zebra finch behaviour or physiology. Two studies found effects on sexual imprinting and song learning behaviour (Mann et al. 1991; Vos et al. 1993). Two studies found effects on the visual system (Bredenkötter \& Bischof 2003; Eckmeier \& Bischof 2008). Nevertheless, a recent molecular analysis found that white morphs represented a distinct genetic cluster, reflecting their history of selective breeding (Hoffman et al. 2014). In the process of selecting for these colour variants, there may have been unintentional side effects on other traits, through genetic hitchhiking, selective sweeps or epistasis. While there have been no investigations of this in the zebra finch, there are examples in other domesticated systems (e.g. rats: Will et al. 2003; Overstreet et al. 2005; dogs: Sutter et al. 2004). The effects of such genetic correlations in the zebra finch might be particularly likely, given that the genome of the domesticated zebra finch consists of few, relatively large linkage blocks compared with other vertebrate genomes (Backström et al. 2010).

As well as potential divergence between different domesticated populations, most studied birds are part of small isolated populations, vulnerable to inbreeding. Studies of one of the larger research populations have demonstrated that experimental full-sibling pairings suffering reduced reproductive success (Bolund et al. 2010). Individuals actively avoid mating with familiar siblings (Ihle \& Forstmeier 2013), and a recent study of another captive population revealed a sensitivity to olfactory cues of kinship, with females reducing reproductive investment when paired with close relatives (Caspers et al. 2015). As stressful environments can exacerbate the effects of inbreeding (Armbruster \& Reed 2005), housing and other stressors that differ across laboratories might drive variation in the effect of inbreeding depression across different studies, as well as the frequency of deleterious alleles will vary due to population history. Therefore, the further consideration of the genetic background and stochastic differences between different study populations may help to explain some differences in the research outcomes across studies, and these might be better resolved with new genomic approaches (e.g. Mortazavi et al. 2008; Wang et al. 2009; Metzker 2010; Davey et al. 2011; Ekblom \& Galindo 2011; Ekblom et al. 2014).

\section{Individual differences}

Domesticated zebra finches vary across personality traits such as boldness, exploratory behaviour, activity, neophobia and aggressiveness (Beauchamp 2000; Martins et al. 2007; David \& Cézilly 2011; Schuett et al. 201 lb; Brust et al. 2013), raising questions as to how this might directly or indirectly affect components that determine reproductive success (Schuett et al. 2010).

Personality may influence the speed and willingness with which an individual chooses a mate (David \& Cézilly 2011), and very choosy individuals may simply refrain from pairing with the bird they are allocated, if they are not behaviourally compatible. Over time, this could result in inadvertent selection for less choosy birds in captive-bred populations. A recent study of wild and domesticated populations of the house mouse Mus musculus (Slade et al. 2014) demonstrated significant changes in mate preference behaviour within a few generations.

In species such as the zebra finch with biparental care, mate choice based on assortative mating for personality could moderate sexual conflict in parental care, altering reproductive success (Royle et al. 2010). Pairs with similar personalities may reproduce more successfully because that may allow for greater coordination of reproductive and parental behaviours 
(Schuett et al. 2011a; Mariette \& Griffith 2012a; Both et al. 2005; but see Schielzeth et al. 2010; McCowan et al. 2014).

There is preliminary evidence that some individuals cope better with particular captive conditions (Crino et al. 2016), and some personality types have greater reproductive success in captivity (McCowan et al. 2014). The extent to which these biases generally affect experimental outcomes remains to be determined, but could be an illuminating area of future research. Developmental conditions can also directly affect an individual's mating behaviour and life history more generally. Zebra finches imprint on visual and song phenotypes (Immelmann 1972; Clayton $1990 \mathrm{~b}, \mathrm{c})$ to an extent that subspecies-specific preferences can be easily reversed (reviewed in Clayton 1990a). Phenotypic quality and individual condition can influence both female mate selectivity (Burley \& Foster 2006; Riebel et al. 2009) and phenotypic preferences (Holveck \& Riebel 2010). Furthermore, recent work has demonstrated that the extent of loss of telomere length during early development is correlated with longevity (Heidinger et al. 2012), and it is not hard to imagine that this will also affect the pattern of an individual's reproductive investment strategy throughout life.

\section{Stress physiology}

Individuals can vary substantially in their endocrine responses to environmental stimuli that can, in turn, cause dramatic variation in reproductive behaviours (e.g. Lendvai \& Chastel 2010). For example, in captive zebra finches, some individuals might be more susceptible to stressors associated with housing conditions such as cage conditions, population density and exposure to caregivers. In birds, stressors activate the hypothalamic-pituitary-adrenal (HPA) axis and result in the release of the steroid hormone corticosterone (reviewed in Cockrem 2013). Corticosterone elicits physiological and behavioural responses that help birds prioritize self-maintenance and survival at the expense of reproduction (reviewed in Wingfield $\delta$ Sapolsky 2003). Across bird species, corticosterone is associated with delayed clutch initiation (Salvante $\delta$ Williams 2003; Griffith et al. 2011), reduced incubation (Spencer et al. 2010; Edwards et al. 2013; Thierry et al. 2013), lower nestling provisioning (Almasi et al. 2008), greater nest abandonment (Spée et al. 2011; Strasser \& Heath 2013) and lower reproductive success (fewer offspring fledged; Schmid et al. 2013). In captive zebra finches, individual variation in stress responsiveness could be a mechanism that explains variation in reproductive success within a population. In this scenario, birds that are least responsive to stressors will have the greatest reproductive success.

Stress responsiveness is both heritable and influenced by the early rearing environment (Evans et al. 2006; Spencer et al. 2009; Adkins-Regan et al. 2013), and even by the stress profile of their partners (Monaghan et al. 2012). If birds with low stress responses are more successful at breeding in captivity, this trait will be favoured over time, resulting in captive populations with dampened stress responses. Anecdotally, it is apparent that laboratory populations of birds that are very recently derived from wild birds are much more flighty than domesticated birds (S. C. Griffith and W. Forstmeier pers. obs.). Although not yet systematically explored in zebra finches, physiologically dampened stress responses have been documented in grey partridges (Perdix perdix) and white-backed munia (Lonchura striata) with wild-derived birds having higher stress responses compared with domesticated congeners (Suzuki et al. 2012; Homberger et al. 2013). Corticosterone has broad pleiotropic effects on physiology and behaviour (Sapolsky 2000). Inadvertent selection for individuals with low stress responses is likely to have organismal consequences beyond modifications in stress physiology.

Individual- and population-level HPA axis characteristics may provide a useful way of comparatively testing the deleterious physiological effects of potential sources of reproductive failure as reviewed herein. For example, studies using direct measures of corticosterone can evaluate the relative stress of widespread practices such as forced-pairing (Griffith et al. 2011), mate separation (Remage-Healey et al. 2003; Perez et al. 2012), food restriction (Spencer et al. 2005) and housing conditions such as artificial lighting (Maddocks et al. 2001; Evans et al. 2012). HPA axis characteristics have been used as a tool to diagnose the stressfulness of housing conditions and the efficacy of breeding programmes in zoo animals (Shepherdson et al. 2004; Scarlata et al. 2012), the effect of anthropogenic disturbance on reproductive success in free-living birds (Müllner et al. 2004; Walker et al. 2005; Crino et al. 2011, 2013) and the general welfare of captive animals (Lane 2006; Fanson et al. 2013; Whitham \& Wielebnowski 2013). In summary, identifying the factors associated with housing and experimental procedures that cause stress (as indicated by elevated corticosterone) in breeding zebra finches will allow researchers to mitigate stressful practices and capture reproductive success across a wider range of phenotypes in captive populations, that is reducing the strength of 
selection for "stressor-resistant" phenotypes, and the biases that it introduces.

\section{Part II. Environmental Determinants of Variation in Reproductive Success}

Most research laboratories keep birds in controlled rooms to remove the confounding effects of temperature, light and humidity variation on experimental work, but set points do vary for these parameters (see Table 1). Other sources of variation between research laboratories will also include differences in housing conditions and basic husbandry practices. In the wild, zebra finches are opportunistic breeders that use a range of environmental cues to optimize reproductive success (Zann 1996). In contrast to the generally predictable and primarily photoperiod-dependent development of reproductive systems typical of seasonally breeding passerines (reviewed in Dawson et al. 2001; Sharp 2005), the physiological reproductive axis of zebra finches can respond rapidly to favourable breeding conditions, seemingly at any time of year, despite showing some seasonality to their reproduction (Perfito et al. 2006; Williamson et al. 2008; Zann 1996; reviewed in Hahn et al. 2008). However, individual pairs vary in the timing of breeding in response to these environmental cues, leading to a relatively low level of breeding synchrony within a local population (Zann et al. 1995; Griffith et al. 2008; Mariette \& Griffith 2012a). This reproductive plasticity means that for domesticated zebra finches even slight variation in housing conditions (e.g. light regime, humidity, food quality, housing density) may have significant repercussions on breeding success. For example, although photo-stimulation appears to affect testes size (Bentley et al. 2000), it is thought that this effect is due to the extended feeding times available at longer daylengths (Perfito et al. 2008). Both field and laboratory studies indicate that individuals are not constantly in a state of breeding readiness, but rather they cycle through breeding and non-breeding periods, which correspond to distinct neuroendocrine states (Perfito et al. 2007; Prior et al. 2013). Even under constant environmental conditions, it may be the case that individual zebra finches will regulate their breeding activity and go through periods of breeding rest and may not be physiologically ready to breed when an experiment is started.

\section{Indoor vs. outdoor housing}

Across studies, there is extensive variation in the basic housing conditions in which breeding birds are kept (see Table 1). For example, some populations of zebra finches are kept in partially outdoor aviaries (e.g. Burley 1986; Gilby et al. 2011; Ihle \& Forstmeier 2013), while others experience only indoor conditions (e.g. Gorman \& Nager 2003; Birkhead et al. 2006). Outdoor and indoor housing environments probably will vary in temperature and humidity (see Humidity and temperature), light quality and quantity, as well as other factors that affect the health and well-being of captive breeding birds. For example, in poultry, individuals kept outdoors with direct access to sunlight are better able to synthesize vitamin $\mathrm{D}$ resulting in better growth and egg production (Lewis \& Gous 2009). The natural lighting of outdoor housing can also be less stressful for breeding birds compared with the artificial lighting of indoor housing that can cause an increase in glucocorticoid stress hormones (see Stress Physiology; Evans et al. 2012). Artificial lighting may also vary qualitatively across research laboratories depending on the total luminance and whether full daylight spectrum lights are used.

Housing in outdoor aviaries can also have negative effects on health and reproduction. For example, birds housed in outdoor aviaries may have greater exposure to interspecific transmissions of pathogens resulting in higher levels of disease and morbidity (e.g. Brittingham et al. 1988). Natural weather conditions will be far more variable than indoor conditions and also vary significantly with the local climate geographically. Extreme or unpredictable conditions (e.g. unexpected cold temperatures) could be stressful for breeding adults and nestlings, resulting in nest abandonment or nestling mortality (Lynn \& Kern 2014). However, of course in the wild weather conditions are also variable and birds should be adapted to dealing with them, and indeed the natural variation may have important stimulatory effects (i.e., light, temperature, humidity).

Outdoor aviaries may also be subject to varying levels of environmental background noise depending on location, and that has adverse effects on reproduction (Barber et al. 2009). It is also possible that indoor locations may also be noisy due to the air handling machinery used. Finally, the type of housing tends to determine the number of birds that are held together (e.g. large groups in outdoor aviaries vs. small groups in typically smaller indoor cages), which will also potentially confound attempts to understand the effects of indoor vs. outdoor housing, for the reasons discussed below. 


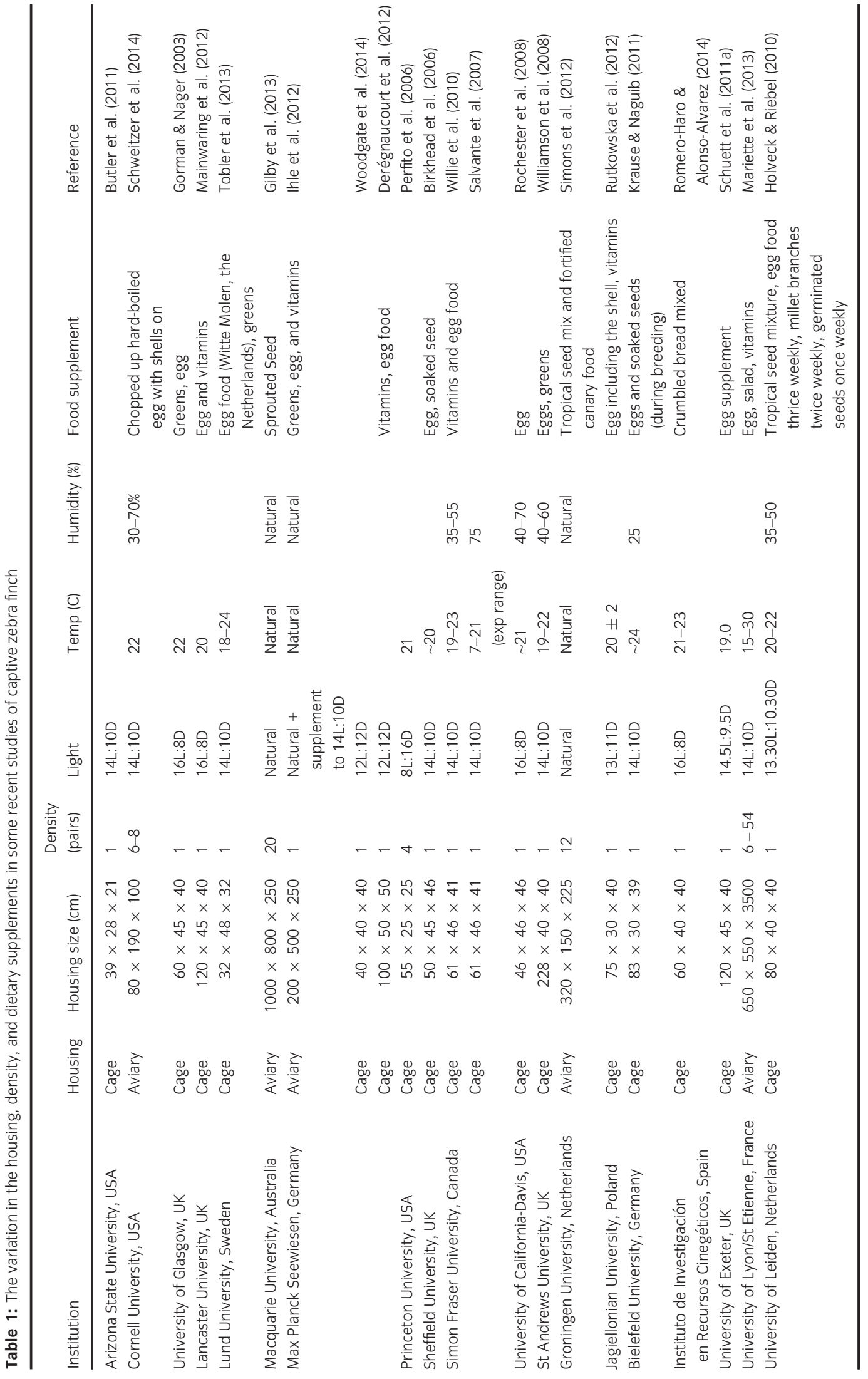




\section{Housing and the social environment}

The composition and density of breeding groups of zebra finches is likely to affect both pair bonding and, in turn, reproductive success. In one of the few studies to investigate the affect of breeding density in aviaries, Poot et al. (2012) found that birds breeding in lower density conditions produced significantly more and larger offspring. Research in both domesticated (Adkins-Regan \& Tomaszycki 2007; Schweitzer et al. 2014) and wild zebra finches (Mariette \& Griffith $2012 \mathrm{~b}$ ) has focused on the importance of the pair bond in this species for successful reproduction. These studies suggest that pairs that are well acquainted, phenotypically similar to one another, or with a high level of behavioural coordination differ from other pairs in a number of aspects of reproduction such as the time taken to initiate breeding or the number of offspring produced. However, there is variation across studies and in research populations in the way in which individuals can form and maintain pairs. Pairs are either allowed to form naturally in aviaries (free choice - but constrained as individuals become paired and are removed from the mating pool), or are determined by the experimenter as a male and female are placed in a cage together (force-paired; Table 2 and references therein). In the zebra finch, females forcepaired to males that are preferred in prior mate choice trials, laid slightly more eggs or laid the first egg of their clutch sooner, compared with females paired with non-preferred males (Balzer \& Williams 1998; Holveck \& Riebel 2010). In their recent study, Ihle et al. (2015) found that individuals that were allowed to freely chose a partner achieved a 37\% higher fitness than did experimentally force-paired birds. That finding is consistent with recent studies in a number of captive-bred zoo species in which animals mated to their preferred partner, rather than to non-preferred or breeding-programme assigned partners (often for genetic management), experienced dramatically increased reproductive success (Martin \& Shepherdson 2012).

In addition to the potential stress caused by forcedpairing, captive zebra finches also experience stress when separated from their partner during or at the end of experiments (Remage-Healey et al. 2003; Perez et al. 2012; Schweitzer et al. 2014), although some of this stress might have been due to the stress of social isolation itself (i.e. being isolated from other conspecifics). Breeding partners are often separated at the end of experiments and birds are kept in single-sex populations before pairing them at a later date with the same or a different partner for another experiment. In the wild, males and females form enduring partnerships and remain close to one another throughout the year (Mariette $\delta$ Griffith 2012 b) with little evidence of infidelity (Griffith et al. 2010) or divorce (Zann 1996). Hence, elevated stress hormones caused by partner separation or forcedpairing could contribute to reduced reproductive success in laboratories (see Stress physiology). There is also likely to be an effect on reproduction of the level of experience that a pair have in breeding together (Adkins-Regan \& Tomaszycki 2007), and yet this is rarely reported or considered methodologically.

The wild zebra finch is a very social bird with individuals nearly always found in the company of small groups of conspecifics (McCowan et al. 2015), and pairs often breeding closely together (Zann 1996; Mariette \& Griffith 2012a). In aviaries, birds will be free to socially interact with many other individuals, whereas when housed in cages, there is likely to be a reduced degree of visual and acoustic communication between individuals in different pairs (cages). There is some evidence from captive birds that reproductive investment is modified by acoustic signals from other members of a loose social group (Waas et al. 2005). This finding is consistent with the observation that in the wild, despite a low level of synchrony across a whole population, pairs nesting very closely to one another synchronize their reproductive activity (Mariette \& Griffith 2012a). However, while social contact can have stimulatory effects on some individuals, there may be inhibitory effects on others (Poot et al. 2012). In the wild, some pairs actively choose to breed alone away from colonies (Mariette \& Griffith 2012a). This may reflect an underlying behavioural polymorphism between social and asocial individuals, with the latter perhaps socially inhibited by the close proximity of others (Dall \& Griffith 2014). Breeding in aviaries, rather than in cages, has the advantage of more closely resembling natural circumstances in which individuals and pairs can act as part of a social network and facilitate each other. However, the social situation in an aviary can create competition for nest sites, nesting material and food, which in turn might result in lower reproductive success for some individuals (McCowan et al. 2014).

Variation in the size and construct of social groups (through housing, see Table 1) will also have consequences for the development of social and sexual behaviour in offspring (Ruploh et al. 2012; Mariette et al. 2013). Reproductive success may be affected by the production of song in adults, with key parameters of song structure (complexity, tempo, stereotypy) and output being affected by the environment (Holveck 


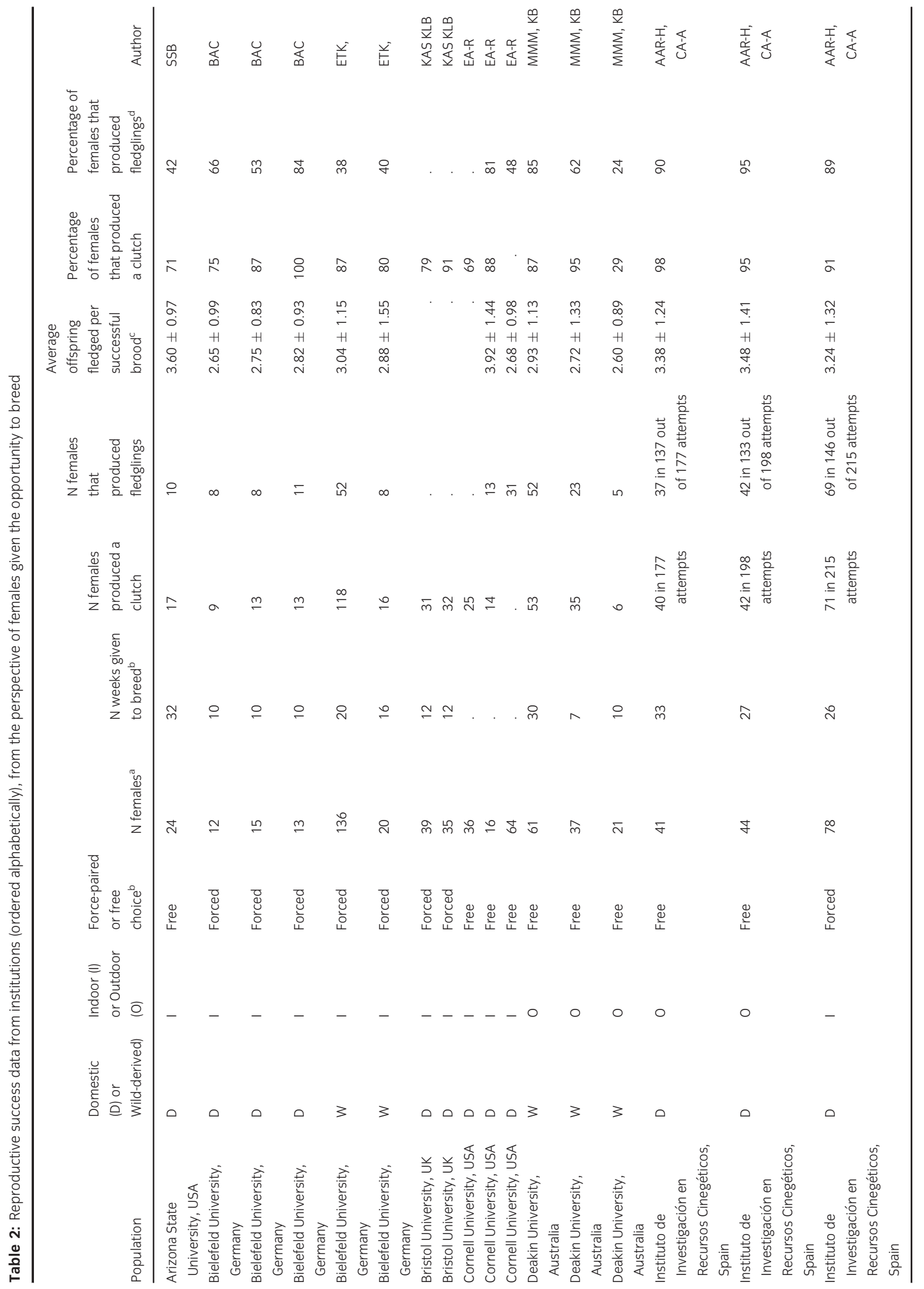




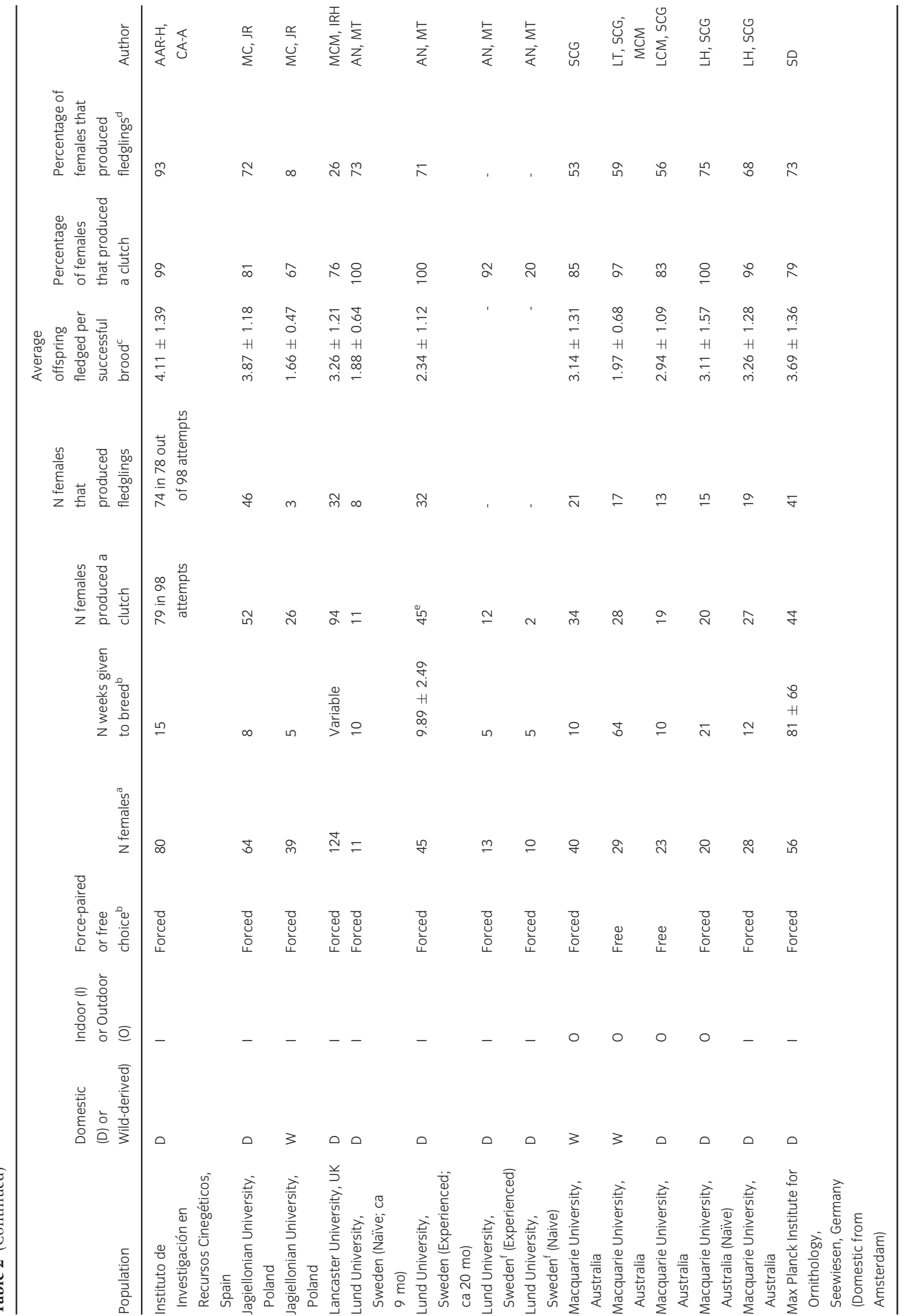




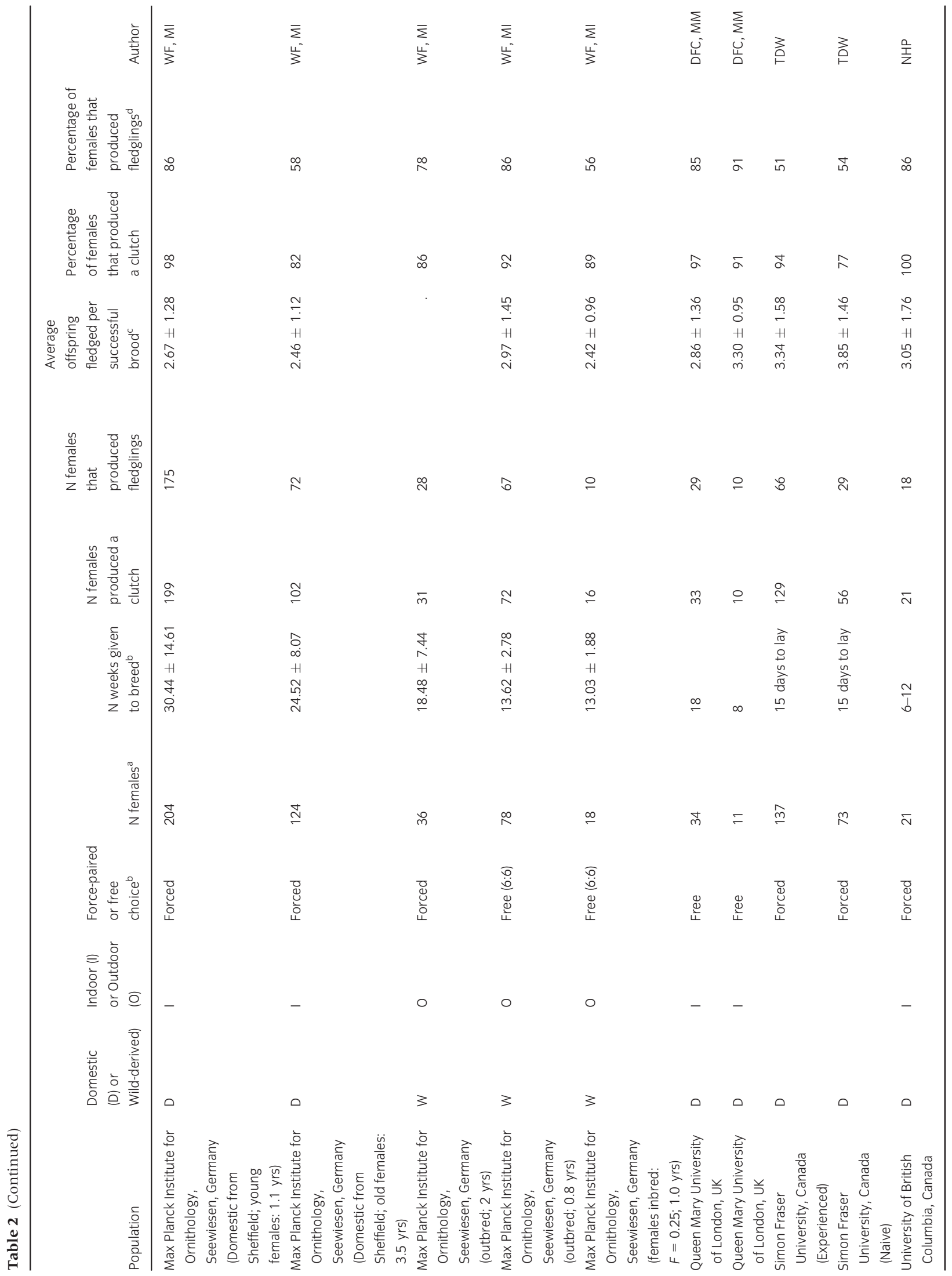




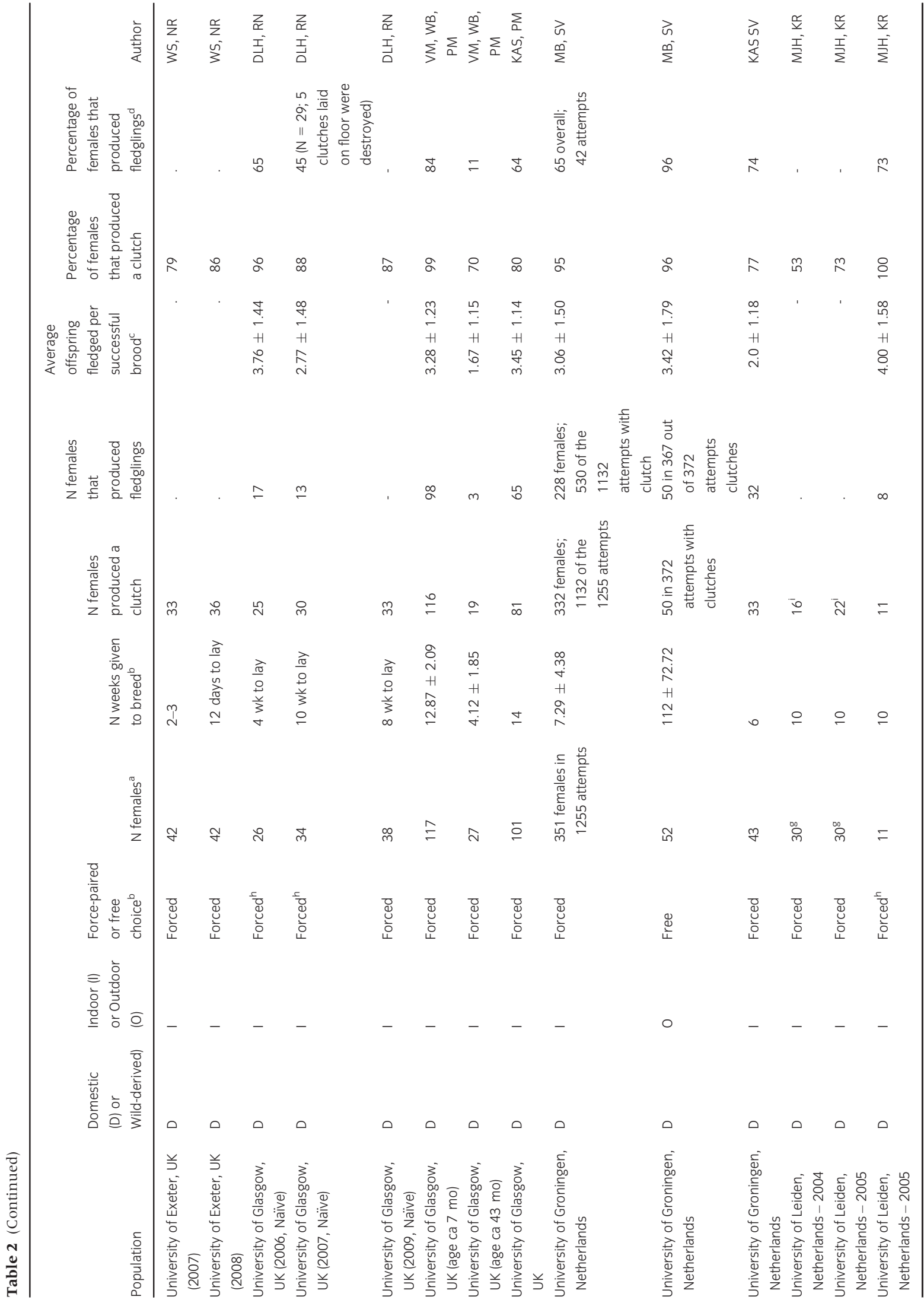




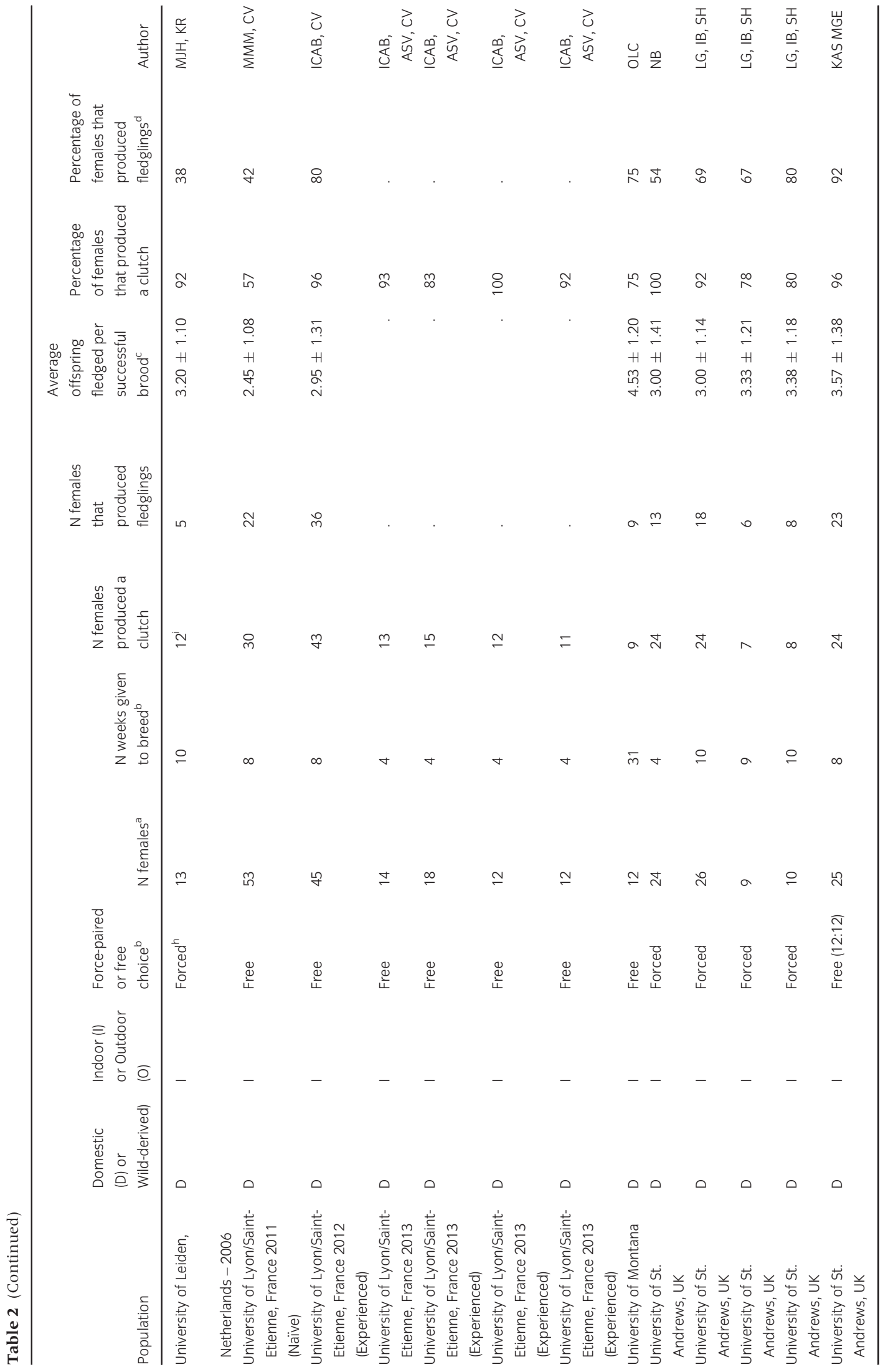




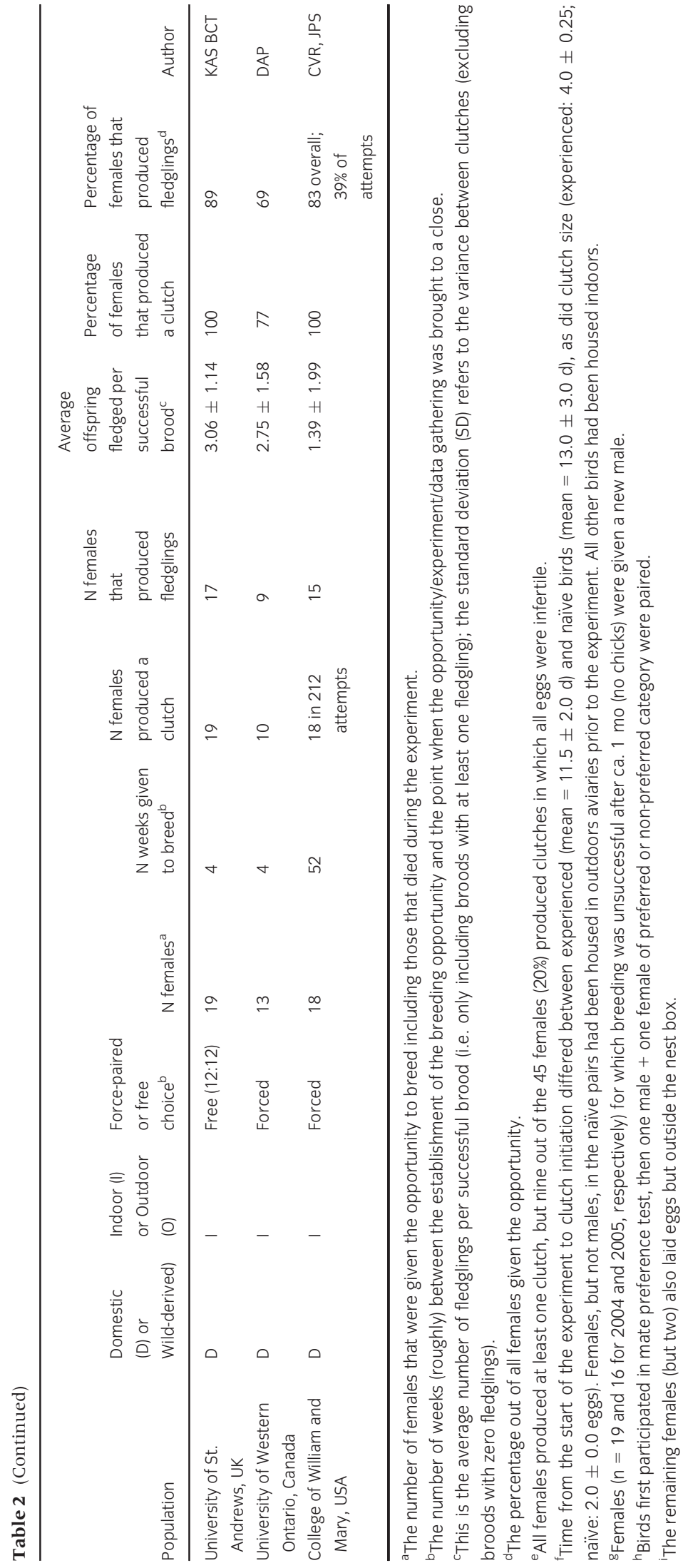


et al. 2008; Brumm et al. 2009) and by the availability of song tutors during early life (Derégnaucourt $2011)$. There is some evidence of reduced variance in song structure between wild and domesticated populations (Slater \& Clayton 1991; Woodgate et al. 2012), and it is possible that there is variation in the quality or variance of song across captive populations. Variation in the expression of song across populations may contribute to heterogeneity in reproductive investment and behaviour given the importance of song in stimulating reproduction (Riebel 2009; Bolund et al. 2012; Woodgate et al. 2012). In addition to affecting the development of song, the early environment also affects the development of song preferences in females (Clayton 1990a; Riebel et al. 2009; Honarmand et al. 2015), and therefore potentially this may vary systematically across populations.

\section{Humidity and temperature}

In wild zebra finches, the trigger of breeding activity has generally been related to rainfall (Zann et al. 1995). Other environmental cues such as humidity and temperature have been shown to both directly (Vleck \& Priedkalns 1985; Cynx 2001) and indirectly (Williams 1996a; Williamson et al. 2008) stimulate reproductive behaviour in zebra finches. Variation in humidity could be an informative cue for zebra finches as it is related to rainfall and groundwater conditions, which influence both water and food availability. However, humidity is often not accounted for in captive studies and a relatively large range is often considered as constant (Table 1). For example, Williams (1996b) considered humidity range of $35-55 \%$ as constant. Williamson et al. (2008) found seasonal patterns of maternal investment in birds breeding in 'constant temperature and humidity rooms' but suggest that the $40-60 \%$ variation in humidity in their study may have been the variable that could have influenced breeding if the birds are sensitive to such changes. Therefore, it appears important to pay attention to even small changes in humidity, as there remains the possibility that variation in humidity in captive breeding environments may affect reproductive output. Unfortunately, it is very difficult to artificially control humidity to a high degree as air-heating systems typically deliver dry air, and humidity is not often controlled to a high level of precision independently of air temperature.

In addition to humidity, variation in temperature is likely to affect reproductive physiology and behaviour in ways that may contribute to variation in reproductive success. Wild zebra finches have been recorded breeding throughout the winter in temperatures as low as $2.2^{\circ} \mathrm{C}$ (Zann et al. 1995), and in summer in temperatures above $40^{\circ} \mathrm{C}$ (Griffith et al. 2016). Periods of low temperature are associated with a reduction or cessation of reproductive activity in wild zebra finches (Davies 1977). Reproductive success in captive birds may be similarly affected by variation in temperature, or across seasons. Captive birds kept at low temperature $\left(7^{\circ} \mathrm{C}\right)$ increased food consumption and time to initiate egg laying and decreased the total number of eggs laid (Salvante et al. 2007). Furthermore, presumably due to the costs of thermoregulation, females reduce the amount of heat transferred to eggs during incubation in low temperature conditions (Nord et al. 2010). The standardized and invariant climatic conditions of captive studies may cause their own problems, but it is worth noting that studies of wild birds generally also rarely report the climatic conditions during which ecological studies are conducted, and these are also likely to cause variation across studies.

\section{Handling and disturbance}

Laboratories may vary in a number of standard procedures relating to the provision of cover, the number of times birds are visited during the day, cleaning routines and the type of interaction that birds get from humans, all of which may lead to different levels of disturbance and stress, which may ultimately result in inadvertent selection on stress-tolerant phenotypes. Alternatively perhaps more disturbance simply leads to a higher level of habituation to such factors. To date, there have been few studies investigating these issues in the zebra finch. Collins et al. (2008) found that the provision of a food reward (fresh greens) directly after handling helped birds to recover normal behaviour more quickly after the disturbance. In the same study, they also investigated the effect of providing cover (part of the cage was covered with an opaque cloth), but found that this actually increased the level of fearfulness over the course of the experiment (Collins et al. 2008). Although they did not look at reproductive performance in the context of these factors, Collins et al. (2008) found that birds that were rewarded after handling were more attractive when testing in a mate choice assay than those that had not been rewarded. The effects of handling or visiting stress on captive animals can be subtle, as seen by significantly different anxiety and pain responses from laboratory rodents in the 
presence of male vs. female research technicians (Sorge et al. 2014).

\section{Diet and nutrition}

The basic diet and nutritional supplements provided to breeding zebra finches vary within and across populations and are likely to influence variation in reproductive investment and success (Monaghan et al. 1996; Williams 1996a; Gorman \& Nager 2003) and diet effects can be long-lasting and span across generations (Naguib et al. 2006). In Table 1, we have summarized some examples of dietary variation across different studies and populations. It is standard practice to provide zebra finches with an ad libitum seed diet, but there can be substantial variation in the quality of food with some diets fortified with vitamins and other supplements. In addition to seed, breeding zebra finches are often supplemented either daily or intermittently with more nutritious foods such as hard-boiled eggs and spinach (Table 1). The diet, often experimentally manipulated, provided to zebra finches prior to and during reproduction can have pervasive effects on reproductive success. For example, females provided with a low-quality diet produce smaller eggs, smaller clutches, have lower hatching success, fledge fewer young and, overall, have lower lifetime reproductive success (Lemon \& Barth 1992; Selman \& Houston 1996; Rutkowska \& Cichoń 2002; Rutstein et al. 2004a,b). In males, diet quality can influence bill and plumage coloration, and courtship rate, all of which may then affect female preference and reproductive investment (Burley et al. 1992; McGraw et al. 2003; Atagan \& Forstmeier 2012).

In addition to variation in diet quality, laboratories also vary in the manner in which food is provided to their breeding birds, which could influence reproductive success. For example, the number of outlets through which a given amount of food can be accessed influences the acquisition of that food by individual birds (e.g. Broom \& Ruxton 2003; Vahl \& Kingma 2007) and large groups of birds in aviaries with a single food dispenser will have to compete much harder than pairs housed in small cages. As a result, in large aviaries, dominant individuals may have greater access to food. Access to food could affect reproductive success by influencing individual decisions about mass regulation (Cuthill et al. 1997), the physiological ability of birds to breed (Rashotte et al. 2001; Sandell et al. 2007) and the expression of condition-dependent sexually selected traits such as bill colour and song rate (Birkhead et al. 1998; Pariser et al. 2010).
Part III. Variation in Reproductive Success Across Laboratories

Here, we characterize the variation across laboratories in the reproductive success of individuals breeding in different contexts. The data we present are unsuitable for directly measuring the extent of selection (because they do not represent lifetime reproductive success). However, they provide a first indication of the extent to which selection might be acting in such populations and also on interpopulation differences. The level of contemporary selection may also affect the composition of experimental data sets. For example, variation between pairs in the latency to lay (when presented with an opportunity to breed) results in a selective pressure determined by the amount of time birds are given to breed. An experimental cut-off of 15 days after individuals are given the opportunity to breed will create a systematic bias with respect to a trait that is significantly related to the latency to lay (such as bill colour, or prior breeding experience). If such relationships exist then, for example, if the research focuses on parental care, then the data will be gathered only on the subset of birds that have bred before the experimental cut-off is reached. It will also affect the composition of subsequent generations if the cut-off determines which individuals produce offspring and which do not. There are anecdotal reports that finch breeders only breed females that lay eggs quickly when given a mate, and this may have resulted in selection over many generations of domestication. There are many logistical reasons why experimental cut-offs are used, and we simply wish to raise an awareness of the sort of bias that they may introduce.

The other obvious source of experimental and population bias is where variation in reproductive success is significantly related to variation in traits such as behaviour or morphology (i.e. natural or sexual selection). Such a relationship will result in larger numbers of offspring being produced by a subset of the adult population, affecting the composition of the population over time. It may also result in biases in experimental samples if an outcome requires the production of a certain number of surviving offspring. For example, if the end point of the research project is to compare either sons and daughters, or extra-pair and within-pair offspring that survive to a certain age, then more data will come from pairs that produce larger broods. If we can start to develop an awareness of such biases, it will help us in the interpretation of results and also enable us to control and reduce such bias in future studies. 


\section{Methods}

The lead author contacted researchers in North America, Europe and Australia (the regions where most of the work on captive zebra finches has been done) that have published research on zebra finches in the past 10 years to request their involvement in this study. A number of researchers did not respond to this initial communication and are therefore not represented, along with other researchers that were unable to, or did not wish to contribute data on these specific questions. The authors of this paper have contributed their own data where applicable and contributed to the writing of the paper. Data were compiled in an effort to determine the proportion of females that produce (1) eggs and (2) fledglings, when given the opportunity to breed (Table 2). For these same pairs, we also report whether they were housed in a cage or aviary, whether they were force-paired or free to choose partners, as well as whether they originated from wild or domestic stock. Contributors provided data from their records, and none of these data were the result of work targeted just at assessing proportional reproductive success. These breeding data were collected as part of researchers' independent ongoing research with this species, which was conducted in line with their own animal ethics approvals and the legal requirements of their respective countries. We collated data from situations in which birds were not subject to experimental manipulations that are likely to have significantly affected their reproduction. In cases in which broods had been switched in cross-fostering experimental designs, we used only the data collected up to the point of the cross-fostering. Most of the data we have gathered and presented come from individuals given a single opportunity to breed. However, we have included a focus on one of the studies in which individuals were allowed to breed repeatedly over an extended period of time. These data (provided by Varian-Ramos and Swaddle, from the College of William \& Mary, United States, summarized in Table 3) provide us with an excellent opportunity to assess the repeatability of reproductive success at an individual level. These data provide important insight into the extent to which reproductive success and failure may be attributable to individual differences. In their study, Varian-Ramos et al. (2014) tracked a total of 33 individuals over a 12-month period in which the birds were allowed to breed ad libitum. We used only the data from the control individuals in that
Table 3: Breeding data from 33 females that were given freedom to breed over a 12-month period in cages at the College of William and Mary, US. Eggs were removed 21 days after the last egg was laid if they had failed to hatch. Offspring were removed from their parents once they had reached independence. The data have been ordered by the number of fledglings produced

\begin{tabular}{|c|c|c|c|c|c|c|}
\hline $\begin{array}{l}\text { Female } \\
\text { ID }\end{array}$ & $\begin{array}{l}\text { No. } \\
\text { clutches }\end{array}$ & No. eggs & No. chicks & $\begin{array}{l}\text { No. } \\
\text { fledge }\end{array}$ & $\begin{array}{l}\% \text { Eggs } \\
\text { hatch }\end{array}$ & $\begin{array}{l}\text { \% Chicks } \\
\text { fledge }\end{array}$ \\
\hline 99 & 16 & 57 & 0 & 0 & 0.0 & NA \\
\hline 121 & 14 & 70 & 5 & 0 & 7.1 & 0.0 \\
\hline 300 & 13 & 33 & 0 & 0 & 0.0 & NA \\
\hline 1555 & 14 & 71 & 5 & 0 & 7.0 & 0.0 \\
\hline 237 & 15 & 72 & 11 & 7 & 15.3 & 63.6 \\
\hline 778 & 4 & 18 & 10 & 7 & 55.6 & 70.0 \\
\hline 206 & 13 & 68 & 29 & 11 & 42.6 & 37.9 \\
\hline 295 & 9 & 70 & 23 & 11 & 32.9 & 47.8 \\
\hline 1000 & 9 & 29 & 14 & 11 & 48.3 & 78.6 \\
\hline 1744 & 9 & 50 & 17 & 11 & 34.0 & 64.7 \\
\hline 1741 & 10 & 62 & 16 & 12 & 25.8 & 75.0 \\
\hline 128 & 11 & 74 & 23 & 13 & 31.1 & 56.5 \\
\hline 257 & 8 & 38 & 16 & 13 & 42.1 & 81.3 \\
\hline 771 & 6 & 25 & 23 & 13 & 92.0 & 56.5 \\
\hline 288 & 14 & 77 & 15 & 14 & 19.5 & 93.3 \\
\hline 1579 & 8 & 68 & 22 & 14 & 32.4 & 63.6 \\
\hline 115 & 8 & 39 & 19 & 15 & 48.7 & 78.9 \\
\hline 1825 & 8 & 45 & 18 & 15 & 40.0 & 83.3 \\
\hline 1682 & 11 & 56 & 25 & 16 & 44.6 & 64.0 \\
\hline 1565 & 7 & 30 & 17 & 17 & 56.7 & 100.0 \\
\hline 1941 & 6 & 22 & 20 & 19 & 90.9 & 95.0 \\
\hline 264 & 11 & 69 & 26 & 21 & 37.7 & 80.8 \\
\hline 218 & 11 & 68 & 26 & 23 & 38.2 & 88.5 \\
\hline 198 & 8 & 44 & 24 & 24 & 54.5 & 100.0 \\
\hline 254 & 8 & 39 & 30 & 25 & 76.9 & 83.3 \\
\hline 1157 & 7 & 36 & 34 & 25 & 94.4 & 73.5 \\
\hline 200 & 6 & 31 & 30 & 25 & 96.8 & 83.3 \\
\hline 1828 & 6 & 30 & 28 & 25 & 93.3 & 89.3 \\
\hline 310 & 9 & 47 & 30 & 29 & 63.8 & 96.7 \\
\hline 355 & 11 & 74 & 33 & 30 & 44.6 & 90.9 \\
\hline 1561 & 8 & 73 & 40 & 31 & 54.8 & 77.5 \\
\hline 1771 & 7 & 35 & 34 & 33 & 97.1 & 97.1 \\
\hline 533 & 11 & 50 & 41 & 34 & 82.0 & 82.9 \\
\hline
\end{tabular}

study, as those birds were not subject to the experimental treatment that was the focus of that work (Varian-Ramos et al. 2014). Varian-Ramos et al. (2014) removed clutches 21 days after the last egg was laid if the eggs failed to hatch, and removed offspring from their parents when they reached independence. One clutch from each pair was removed as part of the study, but all other clutches were left for the parents to hatch and rear. The removed clutch was excluded from analyses, and similarly 12 broods were removed immediately after fledgling and these were excluded from the analysis of those offspring reaching independence. 


\section{Statistical Methods}

Our statistical analyses were focused on addressing individual repeatability of reproductive success, and characterizing variation in reproductive success across and within populations, as well as investigating a couple of likely factors that might determine that variation. The percentage of females in each study that succeeded in clutch initiation and producing at least one fledgling in the across-study data set, and the percentage of breeding attempts per female that were successful in producing either fledglings or independent young in the data from the College of William $\&$ Mary, US; CW Varian-Ramos and JP Swaddle (Table 3) were transformed into binary data (i.e. 1: success, 0: failure) for all the analyses. Intraclass correlation (ICC) was calculated for this success-failure outcome to examine the variability of reproductive success at the level of individual (data from: VarianRamos et al. 2014). The ICC in latent scale (link scale) was estimated based on generalized linear mixed models (GLMMs) with a binomial distribution with logit link function. Models were fitted to the binary success-failure data. The latent scale ICC serves as a measure of variation in the response variable independent of its mean value and is comparable across different sets of data (Nakagawa \& Schielzeth 2010). The models included identity of female as a random effect. Differences between ICC estimates were examined based on posterior probability. Models were fitted, and parameters were estimated with Markov chain Monte Carlo, using software Stan (http://mcstan.org/) called from the $\mathrm{R}$ package rstan (Stan Development Team 2016). Female identity effects on clutch size, the number of fledglings and independent young were tested using a generalized linear model (GLM). The difference between females (those who produced at least one fledgling) in the number of fledglings was examined with a zero-inflated Poisson (ZIP) model with log and logit link functions using $\mathrm{R}$ package pscl (Zeileis et al. 2008).

The effect of several factors on clutch initiation and fledging success was investigated using two separate GLMM with a binomial distribution and logit link function. In both cases, housing condition (indoor vs. outdoor), pairing type (forced vs. free choice) and origin of strain (captive-bred vs. wild-derived) were included as fixed effects. Identity of study and identity of institution were included as random effects. Models were fitted using R package lme4 (Bates et al. 2015). Similarly, the effects of female age were examined using GLM with a binomial distribution and logit link function.

\section{Results}

\section{Individual Repeatability in Reproductive Success}

In the data reported in Table 3, for a set of females over a period of continual breeding (52 wk) 33 females produced 316 clutches $($ mean $=9.58 \pm 2.99$ $\mathrm{SD}$ ). In total, 1670 eggs were laid (mean clutch size $5.32 \pm 1.62 \mathrm{SD})$ and from these eggs 704 chicks hatched (mean per clutch $2.55 \pm 1.66$ SD). From these chicks, 544 birds were fledged (mean per clutch $2.00 \pm 1.52 \mathrm{SD}$; mean per female $16.48 \pm 9.69 \mathrm{SD})$ and 461 independent were produced (mean per clutch $1.82 \pm 1.51 \mathrm{SD}$ ). Overall just $42 \%$ of all eggs laid went on to hatch and just $28 \%$ of eggs produced an offspring that survived to independence. The relationship between the number of fledglings produced in each nest (not accounting for female ID) and the number of independent offspring produced was strong $\left(r^{2}=0.87, \mathrm{df}=138, t\right.$-value $\left.=30.07, \mathrm{p}<0.001\right)$. However, the relationship between the number of hatchlings and fledglings produced was weaker $\left(r^{2}=0.55\right.$, $\mathrm{df}=177, t$-value $=14.80, \mathrm{p}<0.001)$, and the relationship between the production of eggs and production of hatchlings was weaker still $\left(r^{2}=0.088, \mathrm{df}=\right.$ $314, t$-value $=5.51, \mathrm{p}<0.001)$.

Females differed in their clutch size (likelihood ratio test, $\chi^{2}=126.65$, df $=34, \mathrm{p}<0.001, \mathrm{n}=380$ nests, GLM), likelihood of successfully producing fledglings (categorized as a binary variable) $\left(\chi^{2}=171.7, \mathrm{df}=32\right.$, $\mathrm{p}<0.001, \mathrm{n}=316, \mathrm{GLM})$, in the number of fledglings produced in successful broods [that produced at least one fledgling; $\chi^{2}=119.54, \mathrm{df}=32, \mathrm{p}<0.001, \mathrm{n}=316$ (152 were successful), ZIP model, and in the likelihood of producing independent offspring (categorized as a binary variable $)\left(\chi^{2}=159.9, \mathrm{df}=32, \mathrm{p}<0.001\right.$, $\mathrm{n}=304$, GLM); See Fig. 1b]. The proportion of variation explained by interfemale differences did not differ for the success in rearing young to fledging, and in rearing them to independence (for the production of fledglings, Intraclass correlation $($ ICC) $=0.56$, $\mathrm{SE}=0.095, \mathrm{n}=316$ nests; and for independent offspring, $\quad \mathrm{ICC}=0.53, \mathrm{SE}=0.094, \mathrm{n}=304$; posterior probability, $\operatorname{Pr}($ fledging $<$ independence $)=0.45$ ). Both variables were more repeatable than clutch size $(\mathrm{ICC}=0.22, \mathrm{SE}=0.058, \operatorname{Pr}($ fledging $<$ clutch $)=0.0$, $\operatorname{Pr}($ independence $<$ clutch $)=0.004)$.

\section{Cross-Study Comparison of Clutch and Fledging} Success

From Table 2, we combined data from 23 institutions on egg hatching success per female and from 

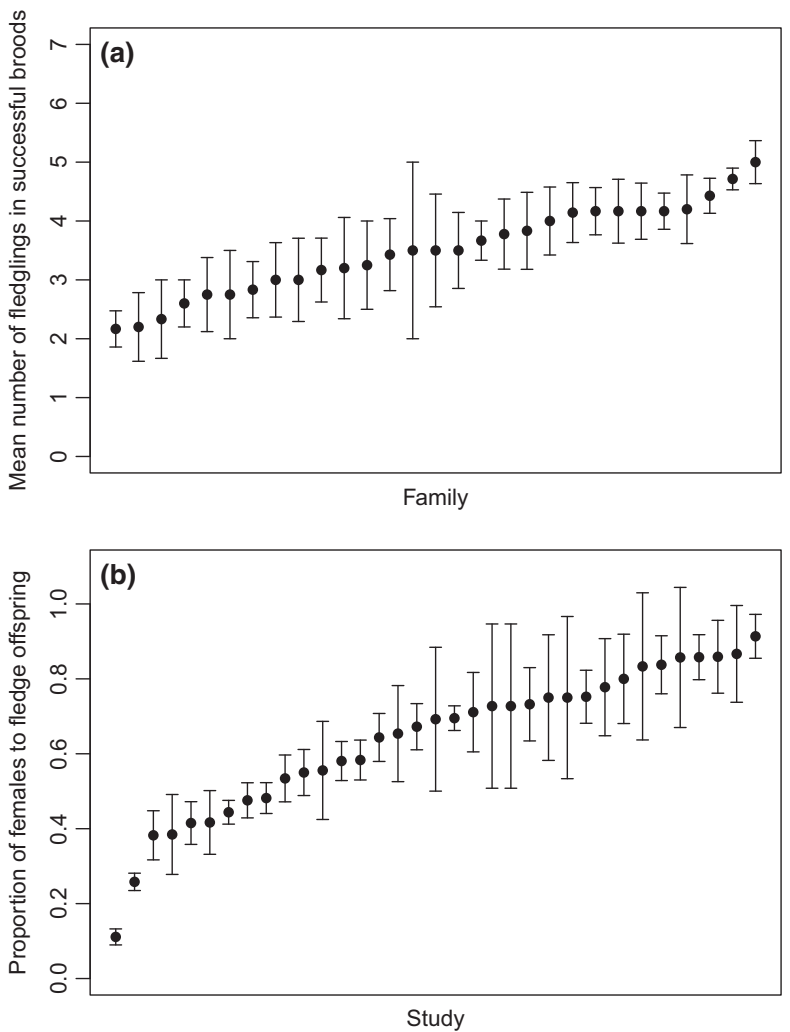

Fig. 1: (a) Mean number ( $\pm S E$ ) of fledglings produced per successful brood across 29 females that were given the opportunity to breed repeatedly across a year, and that raised at least some fledglings successfully (four females failed to fledge any offspring and are therefore not represented). All 29 females were successful but there are signifcant differences in how many fledglings they produced (see results). All data were from the longitudinal study by Varian-Ramos et al. (2014). (b) The proportion of females $( \pm \mathrm{SE})$ that successfully fledged offspring when given the opportunity to breed. Data from 35 studies.

21 institutions on fledgling rearing success per female. In total, 2813 females of 3213 successfully hatched chicks (proportion $=0.88, \mathrm{SE}=0.006$ ), and 1899 females of 2906 raised fledglings (proportion $=0.65, \mathrm{SE}=0.01)$. The probability of females initiating at least one clutch varied across studies $\left(\chi^{2}=136.96, \mathrm{df}=1, \mathrm{p}<0.001, \mathrm{n}=3213\right.$ females, 70 studies, 23 institutions, GLMM) but not across institutions $\left(\chi^{2}=0.0008, \quad \mathrm{df}=1, \mathrm{p}=0.98\right)$. Similarly, the probability of producing fledglings was different across studies $\left(\chi^{2}=136.78, \mathrm{df}=1, \mathrm{p}<0.001\right.$, $\mathrm{n}=2906$ females, 57 studies, 21 institutions, GLMM, Fig. 1b) but not across institutions $\left(\chi^{2}=2.5, \mathrm{df}=1, \mathrm{p}=0.11\right)$, suggesting that experimental conditions specific to individual studies explain more variation in egg laying than population-level factors.

\section{Reproduction and Pair and Female Characteristics}

Females were as likely to produce a clutch when housed either indoors or outdoors (Wald test, $z=1.65, \mathrm{p}=0.099, \mathrm{n}=3003$ females, $\mathrm{n}=68$ studies, $\mathrm{n}=20$ institutions, GLMM; Fig. 2a), and when forcepaired or given free choice of partner $(z=0.25$, $\mathrm{p}=0.8$; Fig. $2 \mathrm{~b}$ ), while a higher proportion of females from domestic origin produced a clutch than those from wild-derived populations $(z=-2.08, \mathrm{p}=0.04$; Fig. 2c). Females in indoor cages fledged significantly fewer young than did females breeding in outdoor cages/aviaries $(z=2.42, \mathrm{p}=0.016, \mathrm{n}=2696$ females, 55 studies, 22 institutions, GLMM; Fig. 2d). Females from domesticated strains were more likely to produce fledglings than those in populations derived from the wild more recently $(z=-3.65, \mathrm{p}<0.001$; Fig. 2e). Females that were force-paired by researchers and pairs formed through mate choice were equally likely to fledge young $(z=-0.88, p=0.38$; Fig. 2f). For three institutions, we could compare success of females from two different age categories (all else is presumed to be equal). In two of the three institutions, young females had a greater reproductive success than older ones. In Lund, Sweden, domesticated females (females of 9 vs. 20 mo) were equally likely to produce a clutch (all females were successful, $\mathrm{n}=56)$, and there was no difference in fledging success $(z=0.106, \mathrm{p}=0.92, \mathrm{n}=56$, GLM). In domesticated birds in Glasgow, UK, (females of 7 vs. $43 \mathrm{mo}$ ) younger females were more likely to produce a clutch $(z=3.57, \mathrm{p}<0.001, \mathrm{n}=144, \mathrm{GLM})$, and to fledge young $(z=5.62, \mathrm{p}<0.001, \mathrm{n}=144, \mathrm{GLM})$. At the Max Planck Institute (Seewiesen, Germany), there were comparative age classes across both domesticated and wild-derived birds, allowing two separate comparisons. For domesticated birds (13 vs. $42 \mathrm{mo}$ ), young birds were more successful at producing clutches $(z=-4.214, \mathrm{p}<0.001, \mathrm{n}=328$, GLM) and in fledging offspring $(z=-5.437, \mathrm{p}<0.001, \mathrm{n}=328$, GLM). For wild-derived birds ( 10 vs. $24 \mathrm{mo}$ ), young females also tended to be better at producing clutches $(z=-1.028, \mathrm{p}=0.30, \mathrm{n}=114, \mathrm{GLM})$ and fledglings $(z=-1.073, \mathrm{p}=0.28, \mathrm{n}=114, \mathrm{GLM})$.

\section{Discussion}

We found that a significant percentage (around 35\%) of females do not successfully produce offspring when given the opportunity to breed in the captive context. Approximately half of these females fail to produce a clutch, and the remainder did not successfully raise offspring. For those females that do produce a clutch, 

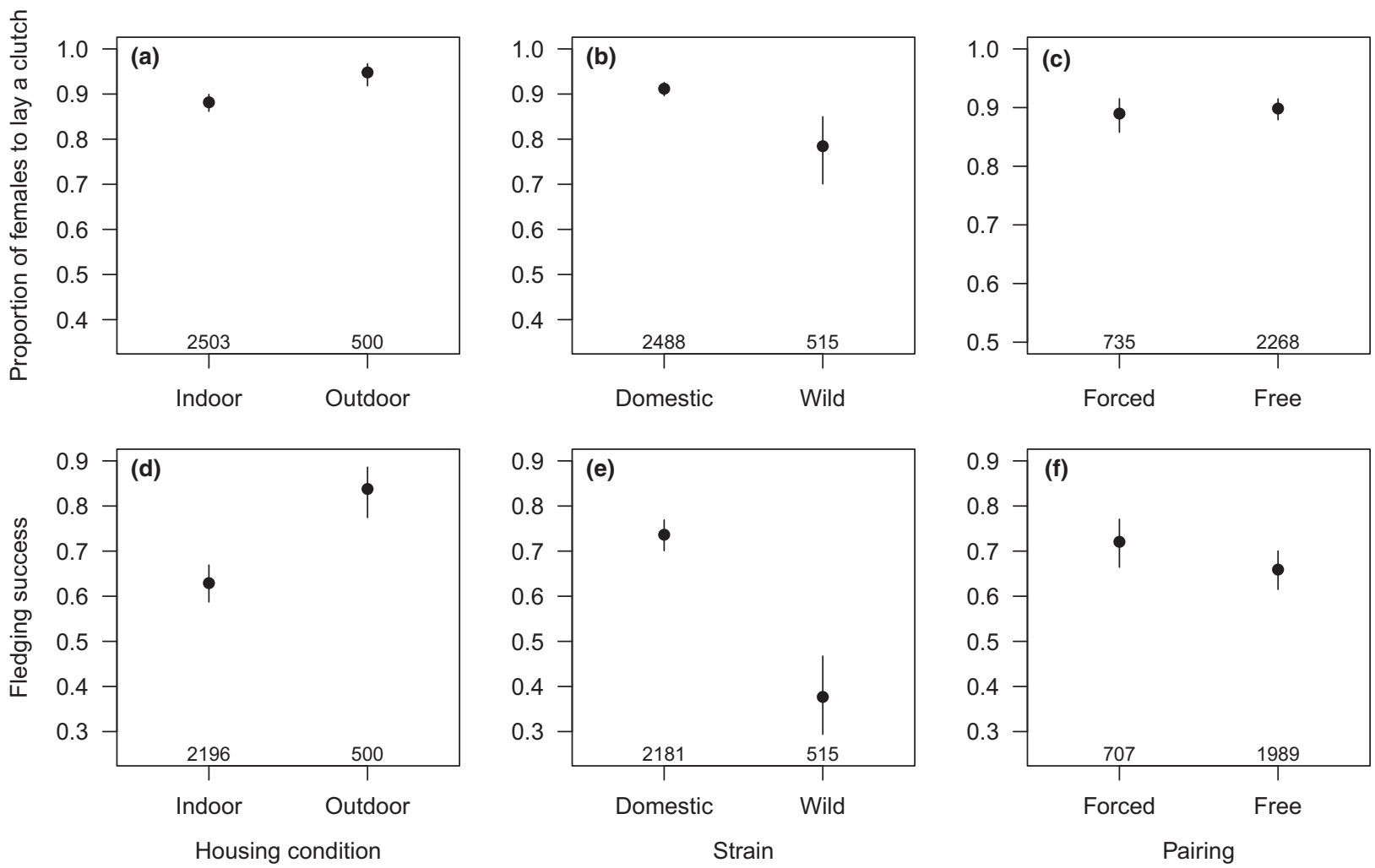

Fig. 2: The reproductive output of females when given the opportunity to breed measured through two metrics: producing a clutch (a-c), and producing fledglings ( $d-f)$. Females were examined across two categories: either housed indoors or outdoors ( $a$ and d); domestic or wild origin (b and e); force-paired or free choice ( $c$ and f). The graphs show predicted mean ( \pm SE) from GLMM. The numbers on the graphs are the number of females used.

the primary determinant of reproductive failure is hatching failure. However, these birds also fail to raise hatched nestlings to fledging and in the subsequent production of independent young. Most of this variation is driven by differences across individual studies rather than differences across institutions. On the one hand, this may perhaps be comforting because it suggests that generally laboratory populations are not hugely different from one another in the way in which they reproduce. However, this does also suggest that variation in reproduction can be driven by the differences in the way that individual studies are set up and that certainly is a cause for concern, because it means that the replicability of results may be challenging even with the same set of birds, if, as yet-unidentified parameters are changed between studies. We suggest that future studies try to identify which of the parameters we have reviewed in Parts I and II are the cause of this interstudy variation.

We also found some evidence that the age of females may affect reproductive outcomes, as younger females were more successful than older females in two of three institutions in which there were data available (the age of young and old females varied across the studies - see results). An important caveat here is that the data that provided the opportunity for the comparison of young and old females did not come from studies that were specifically designed to test that and there are likely to have been other uncontrolled sources of variation. We also found that females that bred outdoors produced a higher number of fledglings than those that bred indoors although those categories also typically correlate with the size of the breeding enclosure (cages vs. aviaries). Again, this finding from the data overall is not from controlled studies designed to test for this difference specifically. We found no evidence of a difference between females that were force-paired, or those that were free to choose their partner (but see Ihle et al. 2015 for a more direct investigation of this that found an effect).

We also found some evidence for a higher level of reproductive success in domesticated birds than in laboratory populations that were recently derived 
from birds taken from the wild. This result is consistent with the idea that selection has lead to traits that improve reproductive performance in captive conditions. We found strong evidence of intrinsic variation in individuals' ability to reproduce in the conditions they were provided, as would be required for selection to act. We found moderate intraclass correlation in reproductive success at the level of individual females, indicating that individual reproductive success was repeatable in the longitudinal data from the College of William and Mary (Table 3, Fig. la). The latter data also illustrate how strong the selection can be, with a large reproductive skew across the females monitored (although of course some of this may have been due to their mate).

It is important to be mindful that the data presented here were not originally collected in order to address these issues. The heterogeneity in the data sets presented and in the context in which the captive populations were held precludes a comprehensive investigation into the sources of variation in breeding success among these research laboratories. Nevertheless, we believe it is worthwhile to consider and highlight the potential sources of variation that might

Table 4: A proposed set of data to be completed in all future publications reporting on work focused on the zebra finch

\begin{tabular}{|c|c|c|}
\hline Aspect & Item & Detail \\
\hline \multirow[t]{3}{*}{ Study design } & N experimental groups & \\
\hline & N control groups & \\
\hline & Nature of replication & For example, whole experiment was conducted twice \\
\hline \multirow[t]{9}{*}{ Numbers used } & $\mathrm{N}$ adult males used & (count all individuals that were initially used) \\
\hline & $\mathrm{N}$ adult females used & \\
\hline & $\mathrm{N}$ females with opportunity to reproduce & \\
\hline & $\mathrm{N}$ females that laid eggs & \\
\hline & $\mathrm{N}$ females that had chicks & \\
\hline & $\mathrm{N}$ females that fledged young & \\
\hline & $\mathrm{N}$ males for which data is presented & \\
\hline & $\mathrm{N}$ females for which data is presented & \\
\hline & $\mathrm{N}$ individuals that died or removed & For example, one bird was removed after injuring a wing \\
\hline \multirow[t]{3}{*}{ Experimental procedures } & Nature of any experimental manipulation & Specify details (i.e. testosterone implant) \\
\hline & Nature of any invasive work & For example, $30 \mu \mathrm{l}$ blood sample during chick rearing \\
\hline & Duration given for breeding opportunity & For example, in weeks \\
\hline \multirow[t]{8}{*}{ Experimental animals } & Domesticated or wild stock & Domesticated or recent Wild origin \\
\hline & Source population & Recent origin of stock (i.e. UK domestic birds) \\
\hline & Variety & Wild-type plumage or colour morph \\
\hline & Age & Less than a year, or greater than a year, or mix \\
\hline & Average mass of adults & Mass in $g$ \\
\hline & Prior breeding experience & Yes/no (or mix) \\
\hline & Allocation of breeding partners & For example, force-paired or free choice \\
\hline & Any bias in selection of individuals & For example, only birds with breeding experience used \\
\hline \multirow[t]{10}{*}{ Housing and husbandry } & Cage/aviary size & Width $\times$ length $\times$ height $(\mathrm{m})$ \\
\hline & $\mathrm{N}$ individuals per cage & \\
\hline & Sex ratio present in each cage & For example, 0.5 (as many males as females) \\
\hline & Any restriction in provision of food & For example, seed provided mixed with husk \\
\hline & Type of nest site provided & For example, wooden nest box, woven basket \\
\hline & Nesting material provided & For example, Hessian fibre, coconut fibre, feathers, grass \\
\hline & $\begin{array}{l}\text { Environmental enrichment or shelter } \\
\text { Indoors or outside }\end{array}$ & For example, shelter in $1 / 3$ of cage \\
\hline & Temperature control & For example, constant $25^{\circ} \mathrm{C}$, or local outside conditions \\
\hline & Humidity control & For example, $50 \%$ \\
\hline & Light/dark cycle & For example, 14L:10D \\
\hline \multirow[t]{2}{*}{ Results - baseline data } & Average clutch size & Mean $\pm S D$ \\
\hline & Average number of fledglings & Mean \pm SD (excluding zeros) \\
\hline
\end{tabular}


contribute, at least in part, to variation within and between populations in reproductive success of domesticated zebra finches.

\section{Summary}

The ease with which domesticated zebra finches breed in captivity, relative to other birds, has made them a model system for research across a diversity of fields. The zebra finch will remain an excellent model system with which to conduct work both in the wild and in captivity and we wish to sharpen the insight that future studies of this species can provide. We present data showing a large amount of variation in reproductive success across research laboratories. Although this variation is often noted anecdotally, it has not been the focus of any studies to date. Here, we have highlighted several potential factors that often vary between laboratories that could influence variation in reproductive success in domesticated zebra finches.

We accept that there is always likely to be variation in the housing and husbandry practices of different laboratories. Research groups have to make strategic decisions on the basis of space or monetary constraints as well as following different opportunities to optimize local welfare recommendations. However, for some of the parameters examined, there is no obvious reason why some conditions could not be more standardized. For example in Table 1, we can see that most studies are conducted with a day:night ratio of $14: 10 \mathrm{~h}$, and around $22^{\circ} \mathrm{C}$. Perhaps these could be taken by future studies as standard conditions, which would start to reduce the heterogeneity among different studies? Although more standardized conditions across laboratories might be the most desired outcome, at the least we suggest that further consideration should be given to the way heterogeneity in conditions and protocols across different studies may affect outcomes. This may provide insight into why laboratories can find conflicting results when approaching similar questions in the same species (Jennions 1998; Seguin \& Forstmeier 2012).

Our review of the variation in reproductive success within and across laboratories highlights that studies of the captive zebra finch provide excellent opportunities to understand many aspects of reproductive biology, the sources of variation for fitness and the mechanisms of the domestication process. We urge authors to bear these issues in mind when interpreting the findings of their studies on this important model species. We also believe that our findings, and future work on the questions we raise in this species, may provide broader insight into the issues that occur when animals are brought into captivity. This is relevant for fundamental animal-based research, but also for the breeding of animals in conservation programmes that are increasingly called upon to establish source populations that provide organisms to reestablish or supplement wild populations.

Finally, we endorse the recommendation made by Kilkenny et al. (2010) in their paper outlining the ARRIVE guidelines for the reporting of information that will provide a greater degree of contextual information in a standardized way. Such information will facilitate later attempts to review and analyse variation across studies.

\section{Recommendation}

We propose that all future work on captive zebra finches includes the information itemized in Table 4. While some of that information might be considered quite standard information, much of it is not reported in papers focused on captive zebra finches. We suggest that these data could be presented in a Table provided either in the Methods section or as Supplementary material. The information requested in Table 4 is heavily informed by the items outlined in Kilkenny et al.'s (2010) ARRIVE Guidelines and their Table 2 with some additional information that is more relevant to the zebra finch (as discussed above). We advocate that the table be completed and used as is, rather than being modified with fields excluded or additional ones included. A standardized reporting form will facilitate future efforts to harvest and utilize the material presented.

\section{Literature Cited}

Adkins-Regan, E. \& Tomaszycki, M. L. 2007: Monogamy on the fast track. Biol. Lett. 3, 617-619.

Adkins-Regan, E., Banerjee, S. B., Correa, S. M. \& Schweitzer, C. 2013: Maternal effects in quail and zebra finches: behavior and hormones. Gen. Comp. Endocrinol. 190, 34-41.

Almasi, B., Roulin, A., Jenni-Eiermann, S. \& Jenni, L. 2008: Parental investment and its sensitivity to corticosterone is linked to melanin-based coloration in barn owls. Horm. Behav. 54, 217-223.

Alonso-Alvarez, C., Bertrand, S., Devevey, G., Prost, J., Faivre, B., Chastel, O. \& Sorci, G. 2006: An experimental manipulation of life-history trajectories and resistance to oxidative stress. Evolution 60, 19131924.

Armbruster, P. \& Reed, D. H. 2005: Inbreeding depression in benign and stressful environments. Heredity $\mathbf{9 5}$, $235-242$. 
Atagan, Y. \& Forstmeier, W. 2012: Nutritional enrichment decreases courtship rate in the zebra finch. Anim. Behav. 83, 69-74.

Backström, N., Forstmeier, W., Schielzeth, H., Mellenius, H., Nam, K., Bolund, E., Webster, M. T., Öst, T., Schneider, M., Kempenaers, B. \& Ellegren, H. 2010: The recombination landscape of the zebra finch Taeniopygia guttata genome. Genome Res. 20, 485-495.

Balzer, A. \& Williams, T. 1998: Do female zebra finches vary primary reproductive effort in relation to mate attractiveness? Behaviour 135, 297-309.

Barber, J. R., Crooks, K. R. \& Fristrup, K. M. 2009: The costs of chronic noise exposure for terrestrial organisms. Trends Ecol. Evol. 25, 180-189.

Bates, D., Mächler, M., Bolker, B. \& Walker, S. 2015: Fitting linear mixed-effects models using lme4. J. Stat. Softw. 67, 1-48.

Beauchamp, G. 2000: Individual differences in activity and exploration influence leadership in pairs of foraging zebra finches. Behaviour 137, 301-314.

Bentley, G. E., Spar, B. D., MacDougall-Shackleton, S. A., Hahn, T. P. \& Ball, G. F. 2000: Photoperiodic regulation of the reproductive axis in male zebra finches, Taeniopygia guttata. Gen. Comp. Endocrinol. 117, 449-455.

Birkhead, T. R., Fletcher, F. \& Pellatt, E. J. 1998: Sexual selection in the zebra finch Taeniopygia guttata: condition, sex traits and immune capacity. Behav. Ecol. Sociobiol. 44, 179-191.

Birkhead, T. R., Pellatt, E. J., Matthews, I. M., Roddis, N. J., Hunter, F. M., McPhie, F. \& Castillo-Juarez, H. 2006: Genic capture and the genetic basis of sexually selected traits in the zebra finch. Evolution 60, 2389-2398.

Bolund, E., Schielzeth, H. \& Forstmeier, W. 2009: Compensatory investment in zebra finches: females lay larger eggs when paired to sexually unattractive males. Proc. R. Soc. B Biol. Sci. 276, 707-715.

Bolund, E., Martin, K., Kempenaers, B. \& Forstmeier, W. 2010: Inbreeding depression of sexually selected traits and attractiveness in the zebra finch. Anim. Behav. 79, 947-955.

Bolund, E., Schielzeth, H. \& Forstmeier, W. 2012: Singing activity stimulates partner reproductive investment rather than increasing paternity success in zebra finches. Behav. Ecol. Sociobiol. 66, 975-984.

Both, C., Dingemanse, N. J., Piet, J. D. \& Tinbergen, J. M. 2005: Pairs of extreme avian personalities have highest reproductive success. J. Anim. Ecol. 74, 667-674.

Bredenkötter, M. \& Bischof, H.-J. 2003: Unusual postnatal development of visually evoked potentials in four brain areas of white zebra finches. Brain Res. 978, 155-161.

Brittingham, M. C., Temple, S. A. \& Duncan, R. M. 1988: A survey of the prevalence of selected bacteria in wild birds. J. Wildl. Dis. 24, 299—307.
Broom, M. \& Ruxton, G. D. 2003: Evolutionarily stable kleptoparasitism: consequences of different prey types. Behav. Ecol. 14, 23-33.

Brumm, H., Zollinger, S. A. \& Slater, P. J. B. 2009: Developmental stress affects song learning but not song complexity and vocal amplitude in zebra finches. Behav. Ecol. Sociobiol. 63, 1387-1395.

Brust, V., Wuerz, Y. \& Krüger, O. 2013: Behavioural flexibility and personality in zebra finches. Ethology 119, 559-569.

Burley, N. T. 1986: Sexual selection for aesthetic traits in species with biparental care. Am. Nat. 127, 415-445.

Burley, N. T. \& Foster, V. S. 2006: Variation in female choice of mates: condition influences selectivity. Anim. Behav. 72, 713-719.

Burley, N. T., Price, D. K. \& Zann, R. A. 1992: Bill color, reproduction and condition effects in wild and domesticated zebra finches. Auk 109, 13-23.

Butchart, S. H., Walpole, M., Collen, B., van Strien, A., Scharlemann, J. P., Almond, R. E., Baillie, J. E., Bomhard, B., Brown, C., Bruno, J. \& Carpenter, K. E. 2010 : Global biodiversity: indicators of recent declines. Science 328, 1164-1168.

Butler, M. W., Toomey, M. B. \& McGraw, K. J. 2011 : How many color metrics do we need? Evaluating how different color-scoring procedures explain carotenoid pigment content in avian bare-part and plumage ornaments. Behav. Ecol. Sociobiol. 65, 401-413.

Carr, R. A. \& Zann, R. A. 1986: The morphological identification of domesticated zebra finches, Poephila-Guttata (Passeriformes, Estrilidae), in Australia. Aust. J. Zool. 34, 439.

Caspers, B. A., Gagliardo, A. \& Krause, E. T. 2015: Impact of kin odour on reproduction in zebra finches. Behav. Ecol. Sociobiol. 69, 1827-1833.

Clayton, N. S. 1990a: Assortative mating in zebra finch subspecies, Taeniopygia guttata guttata and T.g. castanotis. Philos. Trans. R. Soc. B. Biol. Sci. 330, 351-370.

Clayton, N. S. 1990b: Subspecies recognition and song learning in zebra finches. Anim. Behav. 40, 10091017.

Clayton, N. S. 1990c: The effects of cross-fostering on assortative mating between zebra finch subspecies. Anim. Behav. 40, 1102-1110.

Cockrem, J. F. 2013: Individual variation in glucocorticoid stress responses in animals. Gen. Comp. Endocrinol. 181, 45-58.

Collins, S. A., Archer, J. A. \& Barnard, C. J. 2008: Welfare and mate choice in zebra finches: effect of handling regime and presence of cover. Anim Welf. 17, 11-17.

Crino, O. L., Van Oorschot, B. K., Johnson, E. E., Malisch, J. L. \& Breuner, C. W. 2011: Proximity to a high traffic road: glucocorticoid and life history consequences for nestling white-crowned sparrows. Gen. Comp. Endocrinol. 173, 323-332. 
Crino, O. L., Johnson, E. E., Blickley, J. L., Patricelli, G. L. \& Breuner, C. W. 2013: Effects of experimentally elevated traffic noise on nestling white-crowned sparrow stress physiology, immune function and life history. J. Exp. Biol. 216, 2055-2062.

Crino, O. L., Buchanan, K. L., Trompf, L. B. S., Mainwaring, M. C. \& Griffith, S. C. 2016: Stress reactivity, condition, and foraging behavior in zebra finches: effects on boldness, exploration, and sociality. Gen. Comp. Endocrinol. doi:10.1016/j.ygcen.2016.01.014.

Cuthill, I. C., Hunt, S., Cleary, C. \& Clark, C. 1997: Colour bands, dominance, and body mass regulation in male zebra finches (Taeniopygia guttata). Proc. R. Soc. B Biol. Sci. 264, 1093-1099.

Cynx, J. 2001: Effects of humidity on reproductive behaviour in male and female zebra finches (Taeniopygia guttata). J. Comp. Psychol. 115, 196-200.

Dall, S. R. X. \& Griffith, S. C. 2014: An empiricist guide to animal personality variation in ecology and evolution. Front. Ecol. Evol. 2, 1-7.

Davey, J. W., Hohenlohe, P. A., Etter, P. D., Boone, J. Q., Catchen, J. M. \& Blaxter, M. L. 2011: Genome-wide genetic marker discovery and genotyping using nextgeneration sequencing. Nat. Rev. Genet. 12, 499-510.

David, M. \& Cézilly, F. 2011 : Personality may confound common measures of mate-choice. PLoS ONE 6, e24778.

Davies, S. J. J. F. 1977: The timing of breeding by the zebra finch Taeniopygia castanotis at Mileura, Western Australia. The Ibis 119, 369-372.

Dawson, A., King, V. M., Bentley, G. E. \& Ball, G. F. 2001: Photoperiodic control of seasonality in birds. J. Biol. Rhythms 16, 365-380.

Derégnaucourt, S. 2011: Birdsong learning in the laboratory, with especial reference to the song of the zebra finch (Taeniopygia guttata). Interact. Stud. 12, 324350 .

Derégnaucourt, S., Saar, S. \& Gahr, M. 2012: Melatonin affects the temporal pattern of vocal signatures in birds. J. Pineal Res. 53, 245-258.

Ducrest, A.-L., Keller, L. \& Roulin, A. 2008: Pleiotropy in the melanocortin system, coloration and behavioural syndromes. Trends Ecol. Evol. 23, 502-510.

Eckmeier, D. \& Bischof, H.-J. 2008: The optokinetic response in wild type and white zebra finches. J. Comp. Physiol. A. 194, 871-878.

Edwards, D. B., Chin, E. H., Burness, G., Gilchrist, H. G. \& Schulte-Hostedde, A. I. 2013: Linking sex differences in corticosterone with individual reproductive behaviour and hatch success in two species of uniparental shorebirds. Comp. Biochem. Physiol. A: Mol. Integr. Physiol. 166, 169-176.

Ekblom, R. \& Galindo, J. 2011: Applications of next generation sequencing in molecular ecology of non-model organisms. Heredity 107, 1-15.
Ekblom, R., Wennekes, P., Horsburgh, G. J. \& Burke, T. 2014: Characterization of the house sparrow (Passer domesticus) transcriptome: a resource for molecular ecology and immunogenetics. Mol. Ecol. Resour. 14, 636646.

Emaresi, G., Bize, P., Altwegg, R., Henry, I., van den Brink, V., Gasparini, J. \& Roulin, A. 2014: Melanin-specific life-history strategies. Am. Nat. 183, 269-280.

Evans, M. R., Roberts, M. L., Buchanan, K. L. \& Goldsmith, A. R. 2006: Heritability of corticosterone response and changes in life history traits during selection in the zebra finch. J. Evol. Biol. 19, 343-352.

Evans, J. E., Smith, E. L., Bennett, A. T. D., Cuthill, I. C. \& Buchanan, K. L. 2012: Short-term physiological and behavioural effects of high-versus low-frequency fluorescent light on captive birds. Anim. Behav. 83, 25-33.

Fanson, K. V., Lynch, M., Vogelnest, L., Miller, G. \& Keeley, T. 2013: Response to long-distance relocation in Asian elephants (Elephas maximus): monitoring adrenocortical activity via serum, urine, and feces. Eur. J. Wildl. Res. 59, 655-664.

Forstmeier, W., Segelbacher, G., Mueller, J. C. \& Kempenaers, B. 2007: Genetic variation and differentiation in captive and wild zebra finches (Taeniopygia guttata). Mol. Ecol. 16, 4039-4050.

Gilby, A. J., Mainwaring, M. C., Rollins, L. A. \& Griffith, S. C. 2011: Parental care in wild and captive zebra finches: measuring food delivery to quantify parental effort. Anim. Behav. 81, 289-295.

Gilby, A. J., Mainwaring, M. C. \& Griffith, S. C. 2013: Incubation behaviour and hatching synchrony differ in wild and captive populations of the zebra finch. Anim. Behav. 85, 1329-1334.

Gilligan, D. M. \& Frankham, R. 2003: Dynamics of genetic adaptation to captivity. Conserv. Genet. 4, 189-197.

Gorman, H. E. \& Nager, R. G. 2003: State-dependent incubation behaviour in the zebra finch. Anim. Behav. 65, $745-754$.

Gorman, H. E., Arnold, K. E. \& Nager, R. G. 2005: Incubation effort in relation to male attractiveness in zebra finches Taeniopygia guttata. J. Avian Biol. 36, 413420.

Griffith, S. C. \& Buchanan, K. L. 2010: The zebra finch: the ultimate Australian supermodel. Emu 110, v-xii.

Griffith, S. C., Pryke, S. R. \& Mariette, M. 2008: Use of nest-boxes by the zebra finch (Taeniopygia guttata): implications for reproductive success and research. Emu 108, $311-319$.

Griffith, S. C., Holleley, C. E., Mariette, M. M., Pryke, S. R. \& Svedin, N. 2010: Low level of extrapair parentage in wild zebra finches. Anim. Behav. 79, 261-264.

Griffith, S. C., Pryke, S. R. \& Buttemer, W. A. 2011: Constrained mate choice in social monogamy and the stress of having an unattractive partner. Proc. Biol. Sci. R. Soc. 278, 2798-2805. 
Griffith, S. C., Mainwaring, M. C., Sorato, E. \& Beckmann, C. 2016: High atmospheric temperatures and "ambient incubation" drive embryonic development and lead to earlier hatching in a passerine bird. R. Soc. Open Sci. 3, $1-14$.

Hahn, T. P., Cornelius, J. M., Sewall, K. B., Kelsey, T. R., Hau, M. \& Perfito, N. 2008: Environmental regulation of annual schedules in opportunistically-breeding songbirds: adaptive specializations or variations on a theme of white-crowned sparrow? Gen. Comp. Endocrinol. 157, 217-226.

Heath, D. D., Heath, J. W., Bryden, C. A., Johnson, R. M. \& Fox, C. W. 2003: Rapid evolution of egg size in captive salmon. Science 299, 1738-1740.

Heidinger, B. J., Blount, J. D., Boner, W., Griffiths, K., Metcalfe, N. B. \& Monaghan, P. 2012: Telomere length in early life predicts lifespan. Proc. Natl Acad. Sci. 109, 1743-1748.

Hoffman, J. I., Krause, E. T., Lehmann, K. \& Krüger, O. 2014: MC1R genotype and plumage colouration in the zebra finch (Taeniopygia guttata): population structure generates artefactual associations. PLoS ONE 9, e86519.

Holveck, M.-J. \& Riebel, K. 2010: Low-quality females prefer low-quality males when choosing a mate. Proc. R. Soc. B 277, 153-160.

Holveck, M.-J., Vieira de Castro, A. C., Lachlan, R. F., ten Cate, C. \& Riebel, K. 2008: Accuracy of song syntax learning and singing consistency signal early condition in zebra finches. Behav. Ecol. 19, 1267-1281.

Homberger, B., Jenni-Eiermann, S., Roulin, A. \& Jenni, L. 2013: The impact of pre- and post-natal contexts on immunity, glucocorticoids and oxidative stress resistance in wild and domesticated grey partridges. Funct. Ecol. 27, 1042-1054.

Honarmand, M., Riebel, K. \& Naguib, M. 2015: Nutrition and peer group composition in early adolescence: impacts on male song and female preference in zebra finches. Anim. Behav. 107, 147-158.

Ihle, M. \& Forstmeier, W. 2013: Revisiting the evidence for inbreeding avoidance in zebra finches. Behav. Ecol. 24, 1356-1362.

Ihle, M., Kempenaers, B. \& Forstmeier, W. 2012: Does hatching failure breed infidelity? Behav. Ecol. 24, 119127.

Ihle, M., Kempenaers, B. \& Forstmeier, W. 2015: Fitness benefits of mate choice for compatibility in a socially monogamous species. PLoS Biol. 13, e1002248.

Immelmann, K. 1972: Sexual and other long-term aspects of imprinting in birds and other species. Adv. Stud. Behav. 4, 147-174.

Jennions, M. D. 1998: The effect of leg band symmetry on female-male association in zebra finches. Anim. Behav. 55, 61-67.

Kilkenny, C., Browne, W. J., Cuthill, I. C., Emerson, M. \& Altman, D. G. 2010: Improving bioscience research reporting: the ARRIVE guidelines for reporting animal research. PLoS Biol. 8, el000412.

Krause, T. \& Naguib, M. 2011 : Compensatory growth affects exploratory behaviour in zebra finches, Taeniopygia guttata. Anim. Behav. 81, 1295-1300.

Lane, J. 2006: Can non-invasive glucocorticoid measures be used as reliable indicators of stress in animals? Anim Welf. 15, 331-342.

Lees, C. M. \& Wilcken, J. 2009: Sustaining the Ark: the challenges faced by zoos in maintaining viable populations. Int. Zoo Yearb. 43, 6-18.

Lemon, W. C. \& Barth, R. H. 1992: The effects of feeding rate on reproductive success in the zebra finch, Taeniopygia guttata. Anim. Behav. 44, 851-857.

Lendvai, A. Z. \& Chastel, O. 2010: Natural variation in stress response is related to post-stress parental effort in male house sparrows. Horm. Behav. 58, 936942.

Lewis, P. D. \& Gous, R. M. 2009: Responses of poultry to ultraviolet radiation. Worlds Poult. Sci. J. 65, 499.

Lynn, S. E. \& Kern, M. D. 2014: Environmentally relevant bouts of cooling stimulate corticosterone secretion in free-living eastern bluebird (Sialia sialis) nestlings: potential links between maternal behavior and corticosterone exposure in offspring. Gen. Comp. Endocrinol.

196, $1-7$.

Maddocks, S. A., Goldsmith, A. R. \& Cuthill, I. C. 2001: The influence of flicker rate on plasma corticosterone levels of European starlings, Sturnus vulgaris. Gen. Comp. Endocrinol. 124, 315-320.

Mainwaring, M. C., Blount, J. D. \& Hartley, I. R. 2012: Hatching asynchrony can have long-term consequences for offspring fitness in zebra finches under captive conditions. Biol. J. Linn. Soc. 106, 430-438.

Mann, N. I., Slater, P. J. B., Eales, L. A. \& Richards, C. 1991: The influence of visual stimuli on song tutor choice in the zebra finch, Taeniopygia guttata. Anim. Behav. 42, 285-293.

Mariette, M. M. \& Griffith, S. C. 2012a: Conspecific attraction and nest site selection in a nomadic species, the zebra finch. Oikos 121, 823-834.

Mariette, M. M. \& Griffith, S. C. 2012 b: Nest visit synchrony is high and correlates with reproductive success in the wild zebra finch Taeniopygia guttata. J. Avian Biol. 43, 131-140.

Mariette, M. M., Cathaud, C., Chambon, R. \& Vignal, C. 2013: Juvenile social experience affects pairing success at adulthood: congruence with the loser effect? Proc. Biol. Sci. R. Soc. 280, 20131514.

Martin, M. S. \& Shepherdson, D. J. 2012: Role of familiarity and preference in reproductive success in ex situ breeding programs. Conserv. Biol. 26, 649656.

Martins, T. L. F., Roberts, M. L., Giblin, I., Huxham, R. \& Evans, M. R. 2007: Speed of exploration and risk-taking 
behavior are linked to corticosterone titres in zebra finches. Horm. Behav. 52, 445-453.

McCowan, L. S. C., Rollins, L. A. \& Griffith, S. C. 2014: Personality in captivity: more exploratory males reproduce better in an aviary population. Behav. Process. 107, 150-157.

McCowan, L. S. C., Mariette, M. M. \& Griffith, S. C. 2015 : The size and composition of social groups in the wild zebra finch. Emu 115, 191-198.

McGraw, K. J., Gregory, A. J., Parker, R. S. \& AdkinsRegan, E. 2003: Diet, plasma carotenoids and sexual coloration in the zebra finch (Taeniopygia guttata). Auk 120, 400.

McKinnon, J. S. \& Pierotti, M. E. R. 2010: Colour polymorphism and correlated characters: genetic mechanisms and evolution. Mol. Ecol. 19, 5101-5125.

Metzker, M. L. 2010: Sequencing technologies - the next generation. Nat. Rev. Genet. 11, 31-46.

Meunier, J., Figueiredo Pinto, S., Burri, R. \& Roulin, A. 2011: Eumelanin-based coloration and fitness parameters in birds: a meta-analysis. Behav. Ecol. Sociobiol. 65, $559-567$.

Monaghan, P., Metcalfe, N. B. \& Houston, D. C. 1996: Male finches selectively pair with fecund females. Proc. R. Soc. B Biol. Sci. 263, 1183-1186.

Monaghan, P., Heidinger, B. J., D'Alba, L., Evans, N. P. \& Spencer, K. A. 2012: For better or worse: reduced adult lifespan following early-life stress is transmitted to breeding partners. Proc. R. Soc. B 279, 709-714.

Mortazavi, A., Williams, B. A., McCue, K., Schaeffer, L. \& Wold, B. 2008: Mapping and quantifying mammalian transcriptomes by RNA-Seq. Nat. Methods $\mathbf{5}$, $621-628$.

Müllner, A., Eduard Linsenmair, K. \& Wikelski, M. 2004: Exposure to ecotourism reduces survival and affects stress response in hoatzin chicks (Opisthocomus hoazin). Biol. Conserv. 118, 549-558.

Naguib, M., Nemitz, A. \& Gil, D. 2006: Maternal developmental stress reduces reproductive success of female offspring in zebra finches. Proc. Biol. Sci. R. Soc. 273, 1901 -1905 .

Nakagawa, S. \& Schielzeth, H. 2010: Repeatability for Gaussian and non-Gaussian data: a practical guide for biologists. Biol. Rev. Camb. Philos. Soc. 85, 935-956.

Nord, A., Sandell, M. I. \& Nilsson, J. ^. 2010: Female zebra finches compromise clutch temperature in energetically demanding incubation conditions. Funct. Ecol. 24, 1031 $-1036$

Overstreet, D. H., Friedman, E., Mathé, A. A. \& Yadid, G. 2005: The Flinders Sensitive Line rat: a selectively bred putative animal model of depression. Neurosci. Biobehav. Rev. 29, 739-759.

Pariser, E. C., Mariette, M. M. \& Griffith, S. C. 2010: Artificial ornaments manipulate intrinsic male quality in wild-caught zebra finches (Taeniopygia guttata). Behav. Ecol. 21, 264-269.

Pereira, H. M., Leadley, P. W., Proença, V., Alkemade, R., Scharlemann, J. P., Fernandez-Manjarrés, J. F., Araújo, M. B., Balvanera, P., Biggs, R., Cheung, W. W. \& Chini, L. 2010: Scenarios for global biodiversity in the $21 \mathrm{st}$ century. Science 330, 1496-1501.

Perez, E. C., Elie, J. E., Soulage, C. O., Soula, H. A., Mathevon, N. \& Vignal, C. 2012: The acoustic expression of stress in a songbird: does corticosterone drive isolationinduced modifications of zebra finch calls? Horm. Behav. 61, 573-581.

Perfito, N., Bentley, G. \& Hau, M. 2006: Tonic activation of brain GnRH immunoreactivity despite reduction of peripheral reproductive parameters in opportunistically breeding zebra finches. Brain Behav. Evol. 67, 123134.

Perfito, N., Zann, R. A., Bentley, G. E. \& Hau, M. 2007: Opportunism at work: habitat predictability affects reproductive readiness in free-living zebra finches. Funct. Ecol. 21, 291-301.

Perfito, N., Kwong, J. M. Y., Bentley, G. E. \& Hau, M. 2008: Cue hierarchies and testicular development: is food a more potent stimulus than day length in an opportunistic breeder (Taeniopygia g. guttata)? Horm. Behav. 53, 567-572.

Poot, H., ter Maat, A., Trost, L., Schwabl, I., Jansen, R. F. \& Gahr, M. 2012: Behavioural and physiological effects of population density on domesticated Zebra Finches (Taeniopygia guttata) held in aviaries. Physiol. Behav. 105, $821-828$.

Prior, N. H., Heimovics, S. A. \& Soma, K. K. 2013: Effects of water restriction on reproductive physiology and affiliative behavior in an opportunistically-breeding and monogamous songbird, the zebra finch. Horm. Behav. 63, 462-474.

Rashotte, M. E., Sedunova, E. V., Johnson, F. \& Pastukhov, I. F. 2001: Influence of food and water availability on undirected singing and energetic status in adult male zebra finches (Taeniopygia guttata). Physiol. Behav. 74, 533-541.

Remage-Healey, L., Adkins-Regan, E. \& Romero, L. M. 2003: Behavioral and adrenocortical responses to mate separation and reunion in the zebra finch. Horm. Behav. 43, 108-114.

Riebel, K. 2009: Song and female mate choice in zebra finches: a review. Adv. Stud. Behav. 40, 197-238.

Riebel, K., Naguib, M. \& Gil, D. 2009: Experimental manipulation of the rearing environment influences adult female zebra finch song preferences. Anim. Behav. 78, 1397-1404.

Rochester, J. R., Heiblum, R., Rozenboim, I. \& Millam, J. R. 2008: Post-hatch oral estrogen exposure reduces oviduct and egg mass and alters nest-building behavior in 
adult zebra finches (Taeniopygia guttata). Physiol. Behav. 95, 370-380.

Romero-Haro, A. A. \& Alonso-Alvarez, C. 2014: Covariation in Oxidative Stress Markers in the Blood of Nestling and Adult Birds. Physiol. Biochem. Zool. 87, 353-362.

Royle, N. J., Schuett, W. \& Dall, S. R. X. 2010: Behavioral consistency and the resolution of sexual conflict over parental investment. Behav. Ecol. 21, 11251130.

Ruploh, T., Bischof, H.-J. \& Engelhardt, N. 2012: Adolescent social environment shapes sexual and aggressive behaviour of adult male zebra finches (Taeniopygia guttata). Behav. Ecol. Sociobiol. 67, 175-184.

Rutkowska, J. \& Cichoń, M. 2002: Maternal investment during egg laying and offspring sex: an experimental study of zebra finches. Anim. Behav. 64, 817-822.

Rutkowska, J., Martyka, R., Arct, A. \& Cichoń, M. 2012: Offspring survival is negatively related to maternal response to sheep red blood cells in zebra finches. Oecologia 168, 355-359.

Rutstein, A. N., Slater, P. J. B. \& Graves, J. A. 2004a: Diet quality and resource allocation in the zebra finch. Proc. Biol. Sci. R. Soc. 271(Suppl.), S286-S289.

Rutstein, A. N., Gilbert, L., Slater, P. J. B. \& Graves, J. A. 2004b: Mate attractiveness and primary resource allocation in the zebra finch. Anim. Behav. 68, 1087-1094.

Salvante, K. G. \& Williams, T. D. 2003: Effects of corticosterone on the proportion of breeding females, reproductive output and yolk precursor levels. Gen. Comp. Endocrinol. 130, 205-214.

Salvante, K. G., Walzem, R. L. \& Williams, T. D. 2007: What comes first, the zebra finch or the egg: temperature-dependent reproductive, physiological and behavioural plasticity in egg-laying zebra finches. J. Exp. Biol. 210, 1325-1334.

Sandell, M. I., Adkins-Regan, E. \& Ketterson, E. D. 2007: Pre-breeding diet affects the allocation of yolk hormones in zebra finches Taeniopygia guttata. J. Avian Biol. 38, 284-290.

Sapolsky, R. M. 2000: Stress hormones: good and bad. Neurobiol. Dis. 7, 540-542.

Scarlata, C. D., Elias, B. A., Godwin, J. R., Powell, R. A., Shepherdson, D., Shipley, L. A. \& Brown, J. L. 2012: Relationship between fecal hormone concentrations and reproductive success in captive pygmy rabbits (Brachylagus idahoensis). J. Mammal. 93, 759770 .

Schielzeth, H., Bolund, E., Kempenaers, B. \& Forstmeier, W. 2010: Quantitative genetics and fitness consequences of neophilia in zebra finches. Behav. Ecol. 22, $126-134$.

Schmid, B., Tam-Dafond, L., Jenni-Eiermann, S., Arlettaz, R., Schaub, M. \& Jenni, L. 2013: Modulation of the adrenocortical response to acute stress with respect to brood value, reproductive success and survival in the Eurasian hoopoe. Oecologia 173, 33-44.

Schuett, W., Tregenza, T. \& Dall, S. R. X. 2010: Sexual selection and animal personality. Biol. Rev. 85, 217246.

Schuett, W., Dall, S. R. X. \& Royle, N. J. 2011 la: Pairs of zebra finches with similar "personalities" make better parents. Anim. Behav. 81, 609-618.

Schuett, W., Godin, J.-G. J. \& Dall, S. R. X. 2011 b: Do female zebra finches, Taeniopygia guttata, choose their mates based on their "personality"? Ethology 117, 908-917.

Schweitzer, C., Schwabl, H., Baran, N. M. \& AdkinsRegan, E. 2014: Pair disruption in female zebra finches: consequences for offspring phenotype and sensitivity to a social stressor. Anim. Behav. 90, 195-204.

Seguin, A. \& Forstmeier, W. 2012: No band color effects on male courtship rate or body mass in the zebra finch: four experiments and a meta-analysis. PLOS ONE 7, e37785.

Selman, R. G. \& Houston, D. C. 1996: The effect of prebreeding diet on reproductive output in zebra finches. Proc. R. Soc. B Biol. Sci. 263, 1585-1588.

Sharp, P. J. 2005: Photoperiodic regulation of seasonal breeding in birds. Ann. N. Y. Acad. Sci. 1040, 189199.

Shepherdson, D. J., Carlstead, K. C. \& Wielebnowski, N. C. 2004: Cross-institutional assessment of stress responses in zoo animals using longitudinal monitoring of faecal corticoids and behaviour. Anim Welf. 13, 105-113.

Simons, M. J. P., Briga, M., Koetsier, E., Folkertsma, R., Wubs, M. D., Dijkstra, C. \& Verhulst, S. 2012: Bill redness is positively associated with reproduction and survival in male and female zebra finches. PLoS ONE 7, e40721.

Slade, B., Parrott, M. L., Paproth, A., Magrath, M. J. L., Gillespie, G. R. \& Jessop, T. S. 2014: Assortative mating among animals of captive and wild origin following experimental conservation releases. Biol. Lett. 10, 20140656.

Slater, P. J. B. \& Clayton, N. S. 1991: Domestication and song learning in zebra finches Taeniopygia guttata. Emu 91, 126-128.

Sorge, R. E., Martin, L. J., Isbester, K. A., Sotocinal, S. G., Rosen, S., Tuttle, A. H., Wieskopf, J. S., Acland, E. L., Dokova, A., Kadoura, B. \& Leger, P. 2014: Olfactory exposure to males, including men, causes stress and related analgesia in rodents. Nat. Methods 11, 629632.

Sossinka, R. 1970: Domestikationserscheinungen beim Zebrafinken Taeniopygia guttata castanotis (Gould). Zool Jührbucher 97, 455-524.

Spée, M., Marchal, L., Lazin, D., Le Maho, Y., Chastel, O., Beaulieu, M. \& Raclot, T. 2011: Exogenous corticosterone and nest abandonment: a study in a long- 
lived bird, the Adélie penguin. Horm. Behav. 60, 362-370.

Spencer, K. A., Wimpenny, J. H., Buchanan, K. L., Lovell, P. G., Goldsmith, A. R. \& Catchpole, C. K. 2005: Developmental stress affects the attractiveness of male song and female choice in the zebra finch (Taeniopygia guttata). Behav. Ecol. Sociobiol. 58, 423-428.

Spencer, K. A., Evans, N. P. \& Monaghan, P. 2009: Postnatal stress in birds: a novel model of glucocorticoid programming of the hypothalamic-pituitary-adrenal axis. Endocrinology 150, 1931-1934.

Spencer, K. A., Heidinger, B. J., D’Alba, L. B., Evans, N. P. \& Monaghan, P. 2010: Then versus now: effect of developmental and current environmental conditions on incubation effort in birds. Behav. Ecol. 21, 999-1004.

Stan Development Team. 2016: RStan: the R interface to Stan. Version 2.10.1.

Strasser, E. H. \& Heath, J. A. 2013: Reproductive failure of a human-tolerant species, the American kestrel, is associated with stress and human disturbance. J. Appl. Ecol. 50, 912-919.

Sutter, N. B., Eberle, M. A., Parker, H. G., Pullar, B. J., Kirkness, E. F., Kruglyak, L. \& Ostrander, E. A. 2004: Extensive and breed-specific linkage disequilibrium in Canis familiaris. Genome Res. 14, 2388-2396.

Suzuki, K., Yamada, H., Kobayashi, T. \& Okanoya, K. 2012: Decreased fecal corticosterone levels due to domestication: a comparison between the white-backed Munia (Lonchura striata) and its domesticated strain, the Bengalese finch (Lonchura striata var. domestica) with a suggestion for complex song evolution. J. Exp. Zool. A. Ecol. Genet. Physiol. 317, 561-570.

Thierry, A.-M., Massemin, S., Handrich, Y. \& Raclot, T. 2013: Elevated corticosterone levels and severe weather conditions decrease parental investment of incubating Adélie penguins. Horm. Behav. 63, 475-483.

Tobler, M., Sandell, M. I., Chiriac, S. \& Hasselquist, D. 2013: Effects of prenatal testosterone exposure on antioxidant status and bill color in adult zebra finches. Physiol. Biochem. Zool. 86, 333-345.

Tschirren, B., Rutstein, A. N., Postma, E., Mariette, M. \& Griffith, S. C. 2009: Short- and long-term consequences of early developmental conditions: a case study on wild and domesticated zebra finches. J. Evol. Biol. 22, 387-395.

Vahl, W. K. \& Kingma, S. A. 2007: Food divisibility and interference competition among captive ruddy turnstones, Arenaria interpres. Anim. Behav. 74, 1391-1401.

Varian-Ramos, C. W., Swaddle, J. P. \& Cristol, D. A. 2014: Mercury reduces avian reproductive success and imposes selection: an experimental study with adult- or lifetime-exposure in zebra finch. PLoS ONE 9, e95674.

Vleck, C. M. \& Priedkalns, J. 1985: Reproduction in zebra finches: hormone levels and effect of dehydration. Condor 87, 37-46.
Vos, D. R., Prijs, J. \& Tencate, C. 1993: Sexual imprinting in Zebra finch males - a differential effect of successive and simultaneous experience with 2 color morphs. Behaviour 126, 137-154.

Waas, J. R., Colgan, P. W. \& Boag, P. T. 2005: Playback of colony sound alters the breeding schedule and clutch size in zebra finch (Taeniopygia guttata) colonies. Proc. R. Soc. B Biol. Sci. 272, 383-388.

Walker, B. G., Boersma, P. D. \& Wingfield, J. C. 2005: Physiological and behavioral differences in magellanic penguin chicks in undisturbed and tourist-visited locations of a colony. Conserv. Biol. 19, 1571-1577.

Wang, Z., Gerstein, M. \& Snyder, M. 2009: RNA-Seq: a revolutionary tool for transcriptomics. Nat. Rev. Genet. 10, 57-63.

Whitham, J. C. \& Wielebnowski, N. 2013: New directions for zoo animal welfare science. Appl. Ani. Behav. Sci. 147, 247-260.

Will, C. C., Aird, F. \& Redei, E. E. 2003: Selectively bred Wistar-Kyoto rats: an animal model of depression and hyper-responsiveness to antidepressants. Mol. Psychiatry 8, 925-932.

Williams, T. D. 1996a: Intra- and inter-individual variation in reproductive effort in captive-breeding zebra finches (Taeniopygia guttata). Can. J. Zool. 74, 85-91.

Williams, T. D. 1996b: Variation in reproductive effort in female zebra finches (Taeniopygia guttata) in relation to nutrient-specific dietary supplements during egg laying. Physiol. Zool. 69, 1255-1275.

Williamson, K., Gilbert, L., Rutstein, A. N., Pariser, E. C. \& Graves, J. A. 2008: Within-year differences in reproductive investment in laboratory zebra finches (Taeniopygia guttata), an opportunistically breeding bird. Naturwissenschaften 95, 1143-1148.

Willie, J., Travers, M. \& Williams, T. D. 2010: Female zebra finches (Taeniopygia guttata) are chronically but not cumulatively "anemic" during repeated egg laying in response to experimental nest predation. Physiol. Biochem. Zool. 83, 119-126.

Wingfield, J. C. \& Sapolsky, R. M. 2003: Reproduction and resistance to stress: when and how. J. Neuroendocrinol. 15, 711-724.

Woodgate, J. L., Mariette, M. M., Bennett, A. T. D., Griffith, S. C. \& Buchanan, K. L. 2012: Male song structure predicts reproductive success in a wild zebra finch population. Anim. Behav. 83, 773-781.

Woodgate, J. L., Buchanan, K. L., Bennett, A. T. D., Catchpole, C. K., Brighton, R. \& Leitner, S. 2014: Environmental and genetic control of brain and song structure in the zebra finch. Evolution 68, 230-240.

Woodworth, L. M., Montgomery, M. E., Briscoe, D. A. \& Frankham, R. 2002: Rapid genetic deterioration in captive populations: causes and conservation implications. Conserv. Genet. 3, 277-288. 
Zann, R. A. 1996: The Zebra Finch - A Synthesis of Field and Laboratory Studies. Oxford Univ. Press, Oxford.

Zann, R. A., Morton, S. R., Jones, K. R. \& Burley, N. T. 1995: The timing of breeding by zebra finches in relation to rainfall in central Australia. Emu 95, 208-222.

Zeileis, A., Kleiber, K. \& Jackman, S. 2008: Regression models for count data in R. J. Stat. Softw. 27, 1-25. 